\title{
Large-scale MR fluid dampers: modeling, and dynamic performance considerations
}

\author{
G. Yang, ${ }^{a^{*}}$ B.F. Spencer, ${ }^{a}$ Jr., J.D. Carlson ${ }^{\mathrm{b}}$ and M.K. Sain ${ }^{\mathrm{c}}$ \\ ${ }^{a}$ Department of Civil Engineering and Geological Sciences, \\ University of Notre Dame, Notre Dame, IN 46556, USA \\ ${ }^{b}$ Lord Corporation, 110 Lord Drive, Cary, NC 27511, USA \\ ${ }^{c}$ Department of Electrical Engineering, University of Notre Dame, Notre Dame, IN 46556, USA
}

\begin{abstract}
The magnetorheological (MR) damper is one of the most promising new devices for structural vibration reduction. Because of its mechanical simplicity, high dynamic range, low power requirements, large force capacity and robustness, this device has been shown to mesh well with application demands and constraints to offer an attractive means of protecting civil infrastructure systems against severe earthquake and wind loading. In this paper, an overview of the essential features and advantages of MR materials and devices is given. This is followed by the derivation of a quasi-static axisymmetric model of MR dampers, which is then compared with both a simple parallel-plate model and experimental results. While useful for device design, it is found that these models are not sufficient to describe the dynamic behavior of MR dampers. Dynamic response time is an important characteristic for determining the performance of MR dampers in practical civil engineering applications. This paper also discusses issues affecting the dynamic performance of MR dampers, and a mechanical model based on the Bouc-Wen hysteresis model is developed. Approaches and algorithms to optimize the dynamic response are investigated, and experimental verification is provided.
\end{abstract}

Keywords: MR fluids; MR dampers; Dampers; Smart damping devices; Smart materials; Hysteresis model; Parameter estimation; System identification; Rheological technology

\section{Introduction}

Over the past decade, much attention has been given to the use of active control in civil engineering structures for earthquake hazard mitigation. These types of control systems are often called protective systems and offer the advantage of being able to dynamically modify the response of a structure in order to increase its safety and reliability. Although we are now at the point where active control systems have been designed and installed in full-scale structures, the

* Corresponding author. Tel.: +1-219-631-5380; fax: +1-219-631-9236

E-mail address: gyang2@nd.edu 
engineering community has yet to fully embrace this technology. This lack of acceptance stems, in part, from questions of cost effectiveness, reliability, power requirements, etc.

In contrast, passive control devices, including base isolation, metallic yield dampers, friction dampers, viscoelastic dampers, viscous fluid dampers, tuned mass dampers and tuned liquid dampers, are well understood and are an accepted means for mitigating the effects of dynamic loadings [1]. However, passive devices have the limitation of not being capable of adapting to varying usage patterns and loading conditions.

An alternative approach-offering the reliability of passive devices, yet maintaining the versatility and adaptability of fully active systems-is found in semi-active control devices. According to the presently accepted definition, a semi-active control device is one which cannot input energy into the system being controlled [2]. Examples of such devices include electrorheological [3-7] and magnetorheological fluid dampers [7-20], variable orifice dampers [21-25], friction controllable isolators and dampers [26-31], and variable stiffness devices [32-37]. In contrast to active control devices, semi-active control devices do not have the potential to destabilize the structure (in the bounded input - bounded output sense), and most require little power to operate. Recent studies indicate that semi-active dampers can achieve the majority of the performance of fully active systems $[10,12,13,17,38-40]$, thus allowing for the possibility of effective response reduction during both moderate and strong seismic activity. For these reasons, significant efforts have been devoted to the development and implementation of semi-active devices.

This paper presents results for the full-scale development of a specific class of semi-active control devices, magnetorheological (MR) dampers, for civil engineering applications. These devices overcome many of the expenses and technical difficulties associated with semi-active devices previously considered.

\section{MR Fluid Characteristics}

Magnetorheological fluids (or simply "MR" fluids) belong to a class of controllable fluids that respond to an applied field with a dramatic change in their rheological behavior. The essential characteristic of MR fluids is their ability to reversibly change from free flowing, linear viscous liquids to semi-solids having a controllable yield strength in milliseconds when exposed to a magnetic field. Normally, this change is manifested by a very large change in the output force of dampers in which they are used.

The initial discovery and development of MR fluids and devices can be credited to Jacob Rabinow at the US National Bureau of Standards in the late 1940s [41,42]. These fluids are suspensions of micron-sized, magnetizable particles in an appropriate carrier liquid. Normally, MR fluids are free flowing liquids having a consistency similar to that of motor oil. However, in the presence of an applied magnetic field, the particles acquire a dipole moment aligned with the external field that causes particles forming linear chains parallel to the field. This phenomenon can solidify the suspension and restrict the fluid movement. Consequently, the yield strength is developed. The degree of change is related to the magnitude of the applied magnetic field, and 


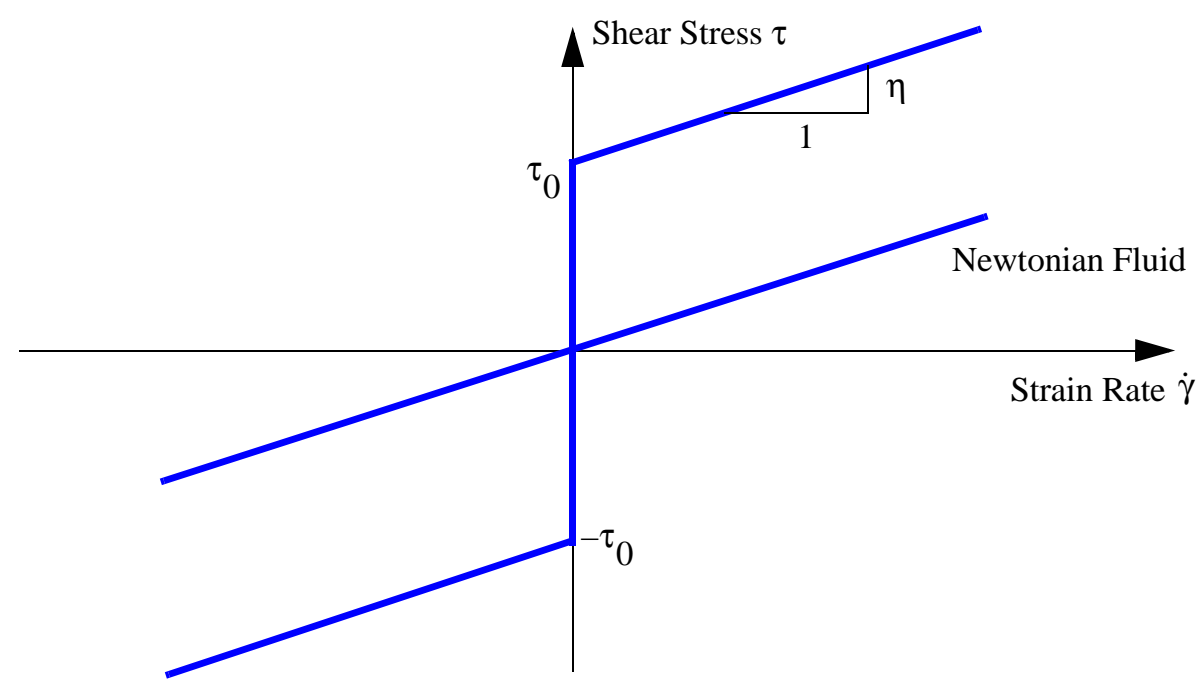

Fig. 1. Bingham plasticity model.

can occur in only a few milliseconds. A simple Bingham plasticity model [43] as shown in Fig. 1 is effective at describing the essential field dependent fluid characteristic. In this model, the total shear stress is given by

$$
\begin{array}{cl}
\tau=\tau_{0}(H) \operatorname{sgn}(\dot{\gamma})+\eta \dot{\gamma} & |\tau|>\left|\tau_{0}\right| \\
\dot{\gamma}=0 & |\tau|<\left|\tau_{0}\right|
\end{array}
$$

where $\tau_{0}=$ yield stress caused by the applied field; $\dot{\gamma}=$ shear strain rate; $H=$ amplitude of the applied magnetic field; and $\eta=$ field-independent post-yield plastic viscosity, which is defined as the slope of the measured shear stress versus the shear strain rate. Recently Lee and Wereley [44], and Wang and Gordaninejad [45] employed the Herschel-Bulkley model to accommodate fluid post-yield shear thinning and shear thickening. In this model, the constant post-yield plastic viscosity in the Bingham model is replaced with a power law model dependent on the shear strain rate. However due to its simplicity, the Bingham model is still very effective, especially in the damper design phase.

The primary advantage of MR fluids stems from their high dynamic yield strength due to the high magnetic energy density that can be established in the fluids. A yield stress close to 100 $\mathrm{kPa}$ can be obtained for MR fluids with magnetic suspensions containing carbonyl iron powder [46]. Carlson and Spencer [9] indicated that a higher dynamic yield stress would allow for smaller device size and higher dynamic range. MR fluids can operate at temperatures from -40 to $150{ }^{\circ} \mathrm{C}$ with only slight variations in yield stress $[46,47]$. From a practical application perspective, MR devices can be powered directly from common, low voltage sources [48,49]. Further, standard electrical connectors, wires and feedthroughs can be reliably used, even in mechanically aggres- 
sive and dirty environments, without fear of dielectric breakdown. Those aspects are particularly promising in earthquake events and cost sensitive applications. The interested reader is directed to reviews on MR fluid characterization and their applications, as presented by Carlson and Spencer [8] and Spencer and Sain [50].

\section{Full-scale seismic MR fluid damper}

To prove the scalability of MR fluid technology to devices of appropriate size for civil engineering applications, a full-scale MR fluid damper has been designed and built [16]. For the nominal design, a maximum damping force of 200,000 N (20 tons) and a dynamic range equal to ten were chosen. A schematic of the large-scale MR fluid damper is shown in Fig. 2. The damper uses a particularly simple geometry in which the outer cylindrical housing is part of the magnetic circuit. The effective fluid orifice is the entire annular space between the piston outside diameter and the inside of the damper cylinder housing. Movement of the piston causes fluid to flow through this entire annular region. The damper is double-ended, i.e. the piston is supported by a shaft at both ends. This arrangement has an advantage in that a rod-volume compensator does not need to be incorporated into the damper, although a small-pressurized accumulator is provided to accommodate thermal expansion of the fluid. The damper has an inside diameter of $20.3 \mathrm{~cm}$ and a stroke of $\pm 8 \mathrm{~cm}$. The electromagnetic coils are wired in three sections on the piston. This results in four effective valve regions as the fluids flow past the piston. The coils contain a total of about $1.5 \mathrm{~km}$ of copper wire. The completed damper is approximately $1 \mathrm{~m}$ long, has a mass of $250 \mathrm{~kg}$, and contains approximately 6 liters of MR fluid. The amount of fluid energized by the magnetic field at any given instant is approximately $90 \mathrm{~cm}^{3}$. A summary of the parameters for the full-scale 20-ton

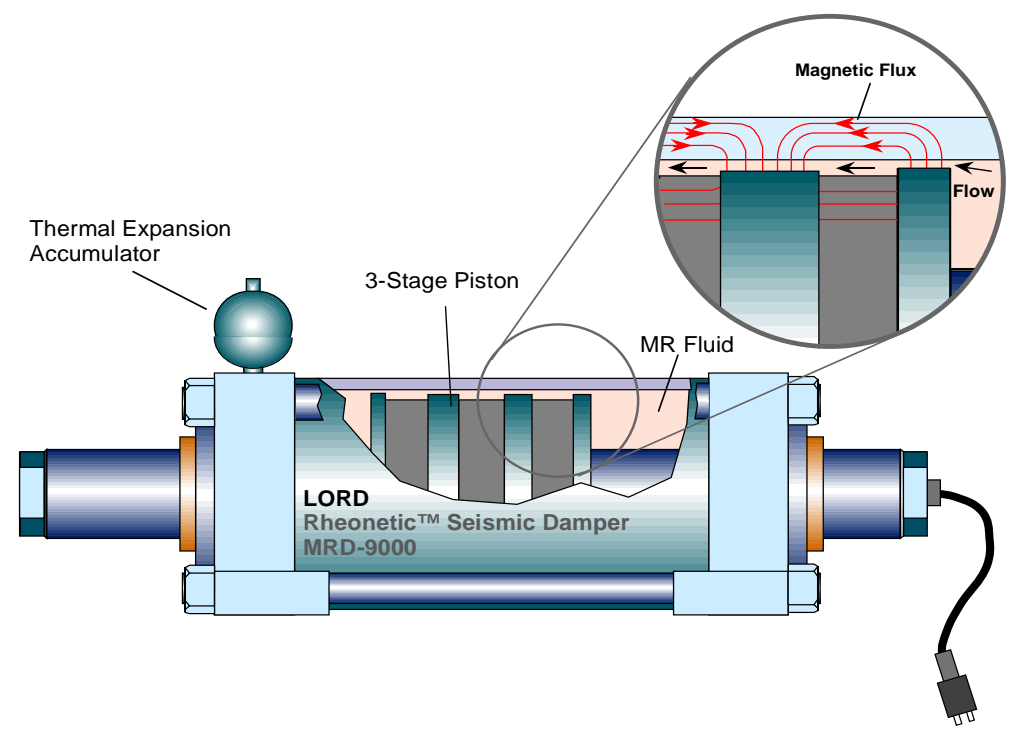

Fig. 2. Schematic of the full-scale 20-ton MR fluid damper. 
MR damper is given in Table 1.

Table 1: Design parameters for the full-scale 20-ton MR damper.

\begin{tabular}{|c|c|}
\hline Stroke & $\pm 8 \mathrm{~cm}$ \\
\hline$F_{\max } / F_{\min }$ & $10.1 @ 10 \mathrm{~cm} / \mathrm{s}$ \\
\hline Cylinder Bore (ID) & $20.32 \mathrm{~cm}$ \\
\hline Max. Input Power & $<50 \mathrm{watts}$ \\
\hline Max. Force (nominal) & $200,000 \mathrm{~N}$ \\
\hline Effective Axial Pole Length & $8.4 \mathrm{~cm}$ \\
\hline Coils & $3 \times 1050 \mathrm{turns}$ \\
\hline Fluid $\eta / \tau_{0 \text { (field) }}^{2}$ & $2 \times 10^{-10} \mathrm{~s} / \mathrm{Pa}$ \\
\hline Apparent Fluid $\eta$ & $1.3 \mathrm{~Pa}-\mathrm{s}$ \\
\hline Fluid $\tau_{0(\text { field })}$ max & $62 \mathrm{kPa}$ \\
\hline Gap & $2 \mathrm{~mm}$ \\
\hline Active Fluid Volume & $\sim 90 \mathrm{~cm}{ }^{3}$ \\
\hline Wire & 16 gauge \\
\hline Inductance $(L)$ & $\sim 6.6$ henries \\
\hline Coil Resistance $(R)$ & $3 \times 7.3 \mathrm{ohms}$ \\
\hline
\end{tabular}

\section{Quasi-static analysis of MR fluid dampers}

During motion of the MR damper piston, fluids flow in the annular gap between the piston and the cylinder housing. For quasi-static analysis of MR fluid dampers, assume that: 1) MR dampers move at a constant velocity; 2) MR fluid flow is fully developed; and 3) a simple Bingham plasticity model may be employed to describe the MR fluid behavior.

Several efforts have been made to develop quasi-static models for controllable fluid damper analysis. Phillips [43] developed a set of nondimensional variables and a corresponding quintic equation to determine the pressure gradient of the flow through a parallel duct. This approach was utilized by Gavin et al. [4] and Makris et al. [6] in their studies. Wereley and Li [51] developed a similar parallel-plate model utilizing a different set of nondimensional variables. Because most of MR dampers incorporate a cylindrical geometry, an axisymmetric model is necessary to precisely describe their quasi-static behavior. Gavin et al. [4] and Kamath et al. [52] each developed an axisymmetric model. Kamath et al. assumed constant yield stress in the annular gap. To account for the radial field distribution, Gavin et al. assumed that the yield stress satisfied the inverse power law.

In this section, following a procedure similar to that utilized by Gavin et al. [4], a quasistatic axisymmetric model is derived based on the Navier-Stokes equation to predict the damper's force-velocity behavior. The pressure gradient then can be solved numerically. In certain cases, a substantially simpler parallel-plate model is shown to be useful to investigate the damper's behav- 
ior. Experimental verification of analytical results is also provided.

\subsection{Axisymmetric model}

The pressure gradient along the flow is resisted by the fluid shear stress that is governed by the Navier-Stokes equation [53]

$$
\rho \frac{\partial}{\partial t} u_{x}(r)+\frac{\partial}{\partial r} \tau_{r x}(r)+\frac{\tau_{r x}(r)}{r}=\frac{\partial p}{\partial x}
$$

where $u_{x}(r)=$ flow velocity; $\tau_{r x}(r)=$ shear stress; $r$ = radial coordinate; $x=$ logitudinal coordinate; $\rho=$ fluid density; and $\partial p / \partial x=$ pressure gradient.

To analyze the quasi-static motion of the flow inside the damper, the fluid inertial can be neglected [53]. In this case, Eq. (3) can be reduced to

$$
\frac{d}{d r} \tau_{r x}(r)+\frac{\tau_{r x}(r)}{r}=\frac{d p}{d x}
$$

The solution of Eq. (4) is

$$
\tau_{r x}(r)=\frac{1}{2} \frac{d p(x)}{d x} r+\frac{D_{1}}{r}
$$

where $D_{1}$ is equal to a constant which can be evaluated by the boundary conditions. But for oscillatory or unsteady flow, the fluid inertial must be taken into account.

Fig. 3 provides a typical shear stress diagram and velocity profile of the Bingham plastic shear flow in the annular gap. In regions I and II, the shear stress has exceeded the yield stress;

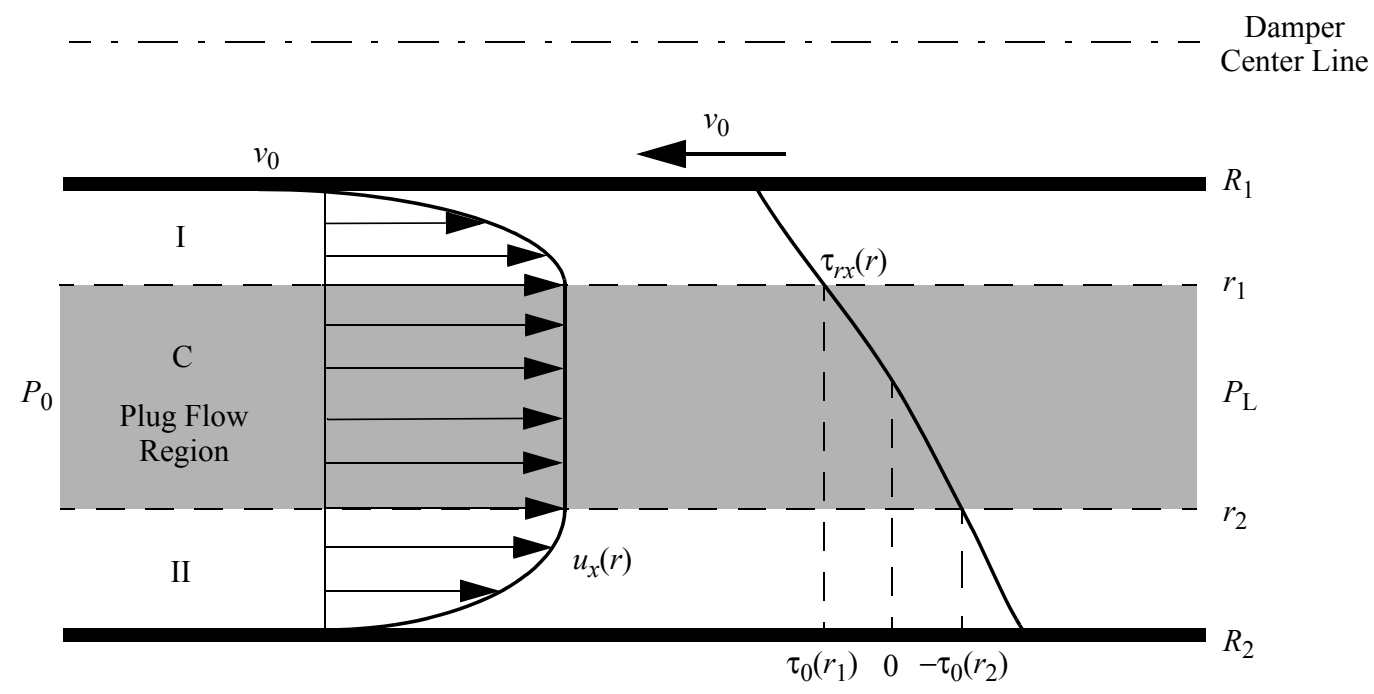

Fig. 3. Stress and velocity profiles through an annular duct. 
therefore, the fluid flows. In region $\mathrm{C}$, the shear stress is lower than the yield stress, so no shear flow occurs; this is often referred to as the plug flow region. The yield stress is assumed to be a monotonic function of radius $r$, therefore, one plug flow region exists when the fluid flows.

In region $\mathrm{I}$, the shear stress $\tau_{r x}(r)$ is given by

$$
\tau_{r x}(r)=\tau_{0}(r)+\eta \frac{d u_{x}(r)}{d r}
$$

This is substitute into Eq. (5) and integrated once with respect to $r$. One obtains

$$
u_{x}(r)=-\frac{1}{4 \eta} \frac{d p}{d x}\left(R_{1}^{2}-r^{2}\right)+\frac{D_{1}}{\eta} \ln \frac{r}{R_{1}}-\frac{1}{\eta} \int_{R_{1}}^{r} \tau_{0}(r) d r-v_{0} \quad R_{1} \leq r \leq r_{1}
$$

by imposing the boundary condition that the flow velocity at $r=R_{1}$ is $u_{x}\left(R_{1}\right)=-v_{0}$.

In region II, the shear stress is given by

$$
\tau_{r x}(r)=-\tau_{0}(r)+\eta \frac{d u_{x}(r)}{d r}
$$

Proceeding as in Region I with boundary condition $u_{x}\left(R_{2}\right)=0$ at outer radius $r=R_{2}$ gives

$$
u_{x}(r)=-\frac{1}{4 \eta} \frac{d p}{d x}\left(R_{2}^{2}-r^{2}\right)-\frac{D_{1}}{\eta} \ln \frac{R_{2}}{r}-\frac{1}{\eta} \int_{r}^{R_{2}} \tau_{0}(r) d r \quad r_{2} \leq r \leq R_{2}
$$

Note that the flow velocity is a constant in the plug flow region because the shear stress is less than the yield stress. The flow velocity at the boundary of the plug flow region satisfies $u_{x}\left(r_{1}\right)=u_{x}\left(r_{2}\right)$. Combining Eqs. (7) and (9) yields

$$
\frac{d p(x)}{d x}\left(R_{2}^{2}-r_{2}^{2}-R_{1}^{2}+r_{1}^{2}\right) / 4+D_{1} \ln \left(R_{2} r_{1} / r_{2} R_{1}\right)+D_{2}-\eta v_{0}=0
$$

where

$$
D_{2}=\int_{r_{2}}^{R_{2}} \tau_{0}(r) d r+\int_{r_{1}}^{R_{1}} \tau_{0}(r) d r
$$

Also the shear stresses $\tau_{r x}$ at $r_{1}$ and $r_{2}$ satisfy $\tau_{r x}\left(r_{1}\right)=\tau_{0}\left(r_{1}\right)$ and $\tau_{r x}\left(r_{2}\right)=-\tau_{0}\left(r_{2}\right)$; therefore, $D_{1}$ can be determined by using Eq. (5):

$$
D_{1}=\frac{r_{1} r_{2}\left(\tau_{0}\left(r_{2}\right) r_{1}+\tau_{0}\left(r_{1}\right) r_{2}\right)}{r_{2}^{2}-r_{1}^{2}}
$$

The expression for the volume flow rate $Q$ is given by 


$$
Q=2 \pi \int_{R_{1}}^{R_{2}} r u_{x}(r) d r
$$

Substitution of Eqs. (7) and (9) into Eq. (13) results in

$$
Q=\pi R_{2}^{2} v_{0}-\frac{\pi}{8 \eta}\left[\frac{d p(x)}{d x}\left(R_{2}^{4}-R_{1}^{4}-r_{2}^{4}+r_{1}^{4}\right)+4 D_{1}\left(R_{2}^{2}-R_{1}^{2}-r_{2}^{2}+r_{1}^{2}\right)+8 D_{3}\right]
$$

where $A_{\mathrm{p}}=$ cross section area of the piston head; $v_{0}=$ piston head velocity; and

$$
D_{3}=\int_{r_{2}}^{R_{2}} \tau_{0}(r) r^{2} d r+\int_{r_{1}}^{R_{1}} \tau_{0}(r) r^{2} d r
$$

Fig. 4 shows a free body diagram of MR fluids through the annular duct. The equation of motion of the fluid materials enclosed by $r=r_{1}$ and $r=r_{2}$ is

$$
\frac{d p}{d x} \pi\left(r_{2}^{2}-r_{1}^{2}\right) d x+2 \pi r_{2} \tau_{0}\left(r_{2}\right) d x+2 \pi r_{1} \tau_{0}\left(r_{1}\right) d x=0
$$

which yields

$$
\frac{d p(x)}{d x}\left(r_{2}^{2}-r_{1}^{2}\right)+2\left[\tau_{0}\left(r_{2}\right) r_{2}+\tau_{0}\left(r_{1}\right) r_{1}\right]=0
$$

By using Eqs. (10-12), (14), (15) and (17), the pressure gradient of the flow $d p / d x, r_{1}$ and $r_{2}$ can be solved numerically [16].

From Eq. (17), the thickness of the plug flow region can be obtained by

$$
r_{2}-r_{1}=-\frac{2\left[\tau_{0}\left(r_{1}\right) r_{1}+\tau_{0}\left(r_{2}\right) r_{2}\right]}{\frac{d p(x)}{d x}\left(r_{1}+r_{2}\right)}
$$

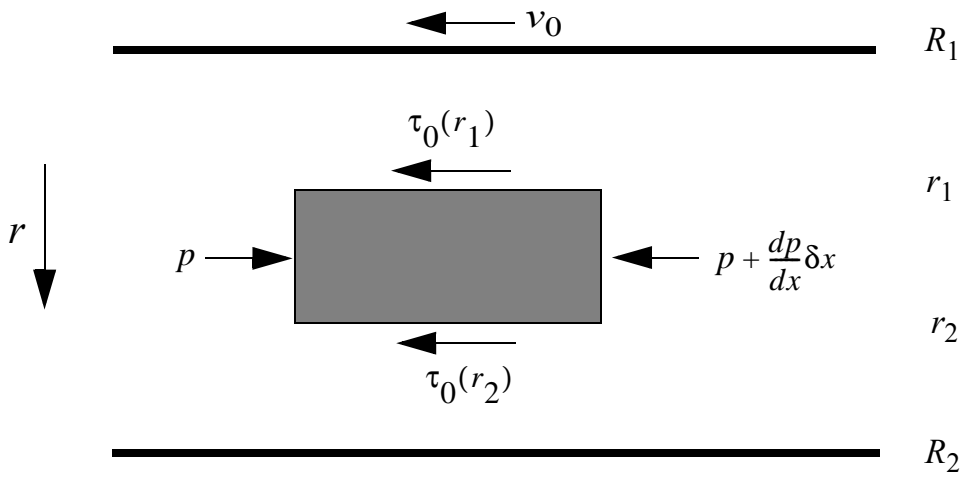

Fig. 4. Free body diagram of MR fluid through an annular duct. 
which varies with the fluid yield stress $\tau_{0}$. Note that flow can only be established when $r_{2}-r_{1}<R_{2}-R_{1}$, which implies that the plug flow needs to be within the gap. Otherwise, there is no flow.

The damper output force is then computed from the equation

$$
F=\Delta p A_{\mathrm{p}}
$$

where $\Delta p=P_{\mathrm{L}}-P_{0}=-L(d p(x) / d x) ; L=$ effective axial pole length; and $A_{\mathrm{p}}=$ cross-section area of the piston head. The shear stress diagram can be determined by Eq. (5), and the velocity profile can be determined by

$$
u_{x}(r)= \begin{cases}-\frac{1}{4 \eta} \frac{d p}{d x}\left(R_{1}^{2}-r^{2}\right)+\frac{D_{1}}{\eta} \ln \frac{r}{R_{1}}-\frac{1}{\eta} \int_{R_{1}}^{r} \tau_{0}(r) d r-v_{0} & R_{1} \leq r \leq r_{1} \\ -\frac{1}{4 \eta} \frac{d p}{d x}\left(R_{2}^{2}-r_{2}^{2}\right)-\frac{D_{1}}{\eta} \ln \frac{R_{2}}{r_{2}}-\frac{1}{\eta} \int_{r_{2}}^{R_{2}} \tau_{0}(r) d r & r_{1} \leq r \leq r_{2} \\ -\frac{1}{4 \eta} \frac{d p}{d x}\left(R_{2}^{2}-r^{2}\right)-\frac{D_{1}}{\eta} \ln \frac{R_{2}}{r}-\frac{1}{\eta} \int_{r}^{R_{2}} \tau_{0}(r) d r & r_{2} \leq r \leq R_{2}\end{cases}
$$

In general, the yield stress $\tau_{0}$ in the axisymmetric model is related to $r$ due to the radial distribution of the magnetic field in the gap. But when $R_{2}-R_{1} \ll R_{1}$, the variation of the yield stress in the gap can be ignored, and Eqs. (11), (12) and (15) be simplified substantially.

\subsection{Parallel-plate model}

Because of the small ratio between the flow gap and the diameter of the damper piston, one might conjecture that the axisymmetric flow field found in the damper can be approximated as flow through a parallel duct, as shown in Fig. 5. To be analogous to the axisymmetric model, the parameter $w$ is taken to be the mean circumference of the damper's annular flow path which is equal to $\pi\left(R_{1}+R_{2}\right)$, and $h$ is taken to be the gap width, equal to $R_{2}-R_{1}$.

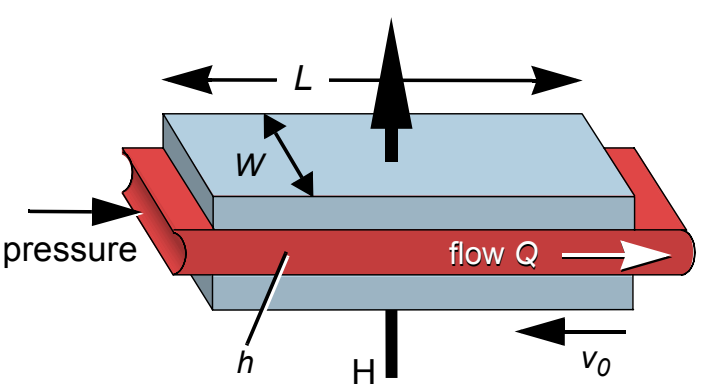

Fig. 5. MR fluid flow through a parallel duct.

The pressure gradient in the flow of a Bingham fluid through a rectangular duct is governed by the quintic equation [43]

$$
3(\mathcal{P}-2 \mathcal{T})^{2}\left(\mathcal{P}^{3}-(1+3 \mathcal{T}-\mathcal{V}) \mathcal{P}^{2}+4 \mathcal{T}^{3}\right)+\mathcal{T} \mathcal{V}^{2} \mathcal{P}^{2}=0 \quad|\mathcal{V}|<3(\mathcal{P}-2 \mathcal{T})^{2} / \mathcal{P}
$$

in which the dimensionless velocity $\mathcal{V}$ of the piston is 


$$
\mathcal{V}=-\frac{w h v_{0}}{2 Q}=-\frac{w h}{2 A_{\mathrm{p}}}
$$

and $\mathcal{P}$ and $\mathcal{T}$ are the dimensionless pressure gradient and dimensionless yield stress, defined by:

$$
\begin{gathered}
\mathcal{P}=-\frac{w h^{3}}{12 Q \eta} \frac{d p}{d x}=-\frac{w h^{3}}{12 A_{\mathrm{p}} v_{0} \eta} \frac{d p}{d x} \\
\mathcal{T}=\frac{w h^{2} \tau_{0}}{12 Q \eta}=\frac{w h^{2} \tau_{0}}{12 A_{\mathrm{p}} v_{0} \eta}
\end{gathered}
$$

Note that when $|\mathcal{V}|>3(\mathcal{P}-2 \mathcal{T})^{2} / \mathcal{P}$, the pressure gradient is governed by equations independent of the dimensionless yield stress $\mathcal{T}$ [43]. Therefore, a controllable yield stress can in no way affect the resisting force of MR dampers.

If the piston head velocity $v_{0}=0$, then $\mathcal{V}=0$, and Eq. (21) becomes a cubic equation for $\mathcal{P}$. This cubic equation has the realizable root at [4]

$$
\mathcal{P}(\mathcal{T})=\frac{2}{3}(1+3 \mathcal{T})\left[\cos \left(\frac{1}{3} \operatorname{acos}\left(1-54\left(\frac{\mathcal{T}}{1+3 \mathcal{T}}\right)^{3}\right)\right)+\frac{1}{2}\right]
$$

In general, Eq. (21) cannot be solved analytically, but a solution may be easily obtained numerically. An approximate solution can be used to estimate the desired root for $0<\mathcal{T}<1000$ and $-0.5<\mathcal{V}<0$, encompassing most practical designs in which the flow is in the opposite direction of the piston velocity

$$
\mathcal{P}(\mathcal{T}, \mathcal{V})=1+2.07 \mathcal{T}-\mathcal{V}+\frac{\mathcal{T}}{1+0.4 \mathcal{T}}
$$

\subsection{Model comparison}

As mentioned previously, the distribution of the yield stress in the gap for the axisymmetric model is related to radius $r$. For simplicity, it is assumed to follow an inverse power law [4]

$$
\tau_{0}(r)=C / r^{n}
$$

where $C$ and $n$ are empirical material constants. A comparison between the parallel-plate and axisymmetric models for $1.5<n<2.5$ is made for the nominal design parameters of the full-scale MR damper shown in Table 1. Note that in the parallel-plate model, the yield stress is assumed to be a constant. Fig. 6 shows the error comparison between the axisymetric and parallel-plate models. This indicates that the maximum error between two models is no more than $0.5 \%$ for $h / R_{2}<0.2$, and less than $2 \%$ for $h / R_{2}<0.4$. Therefore, the simpler parallel-plate model is seen to be adequate for practical design. 


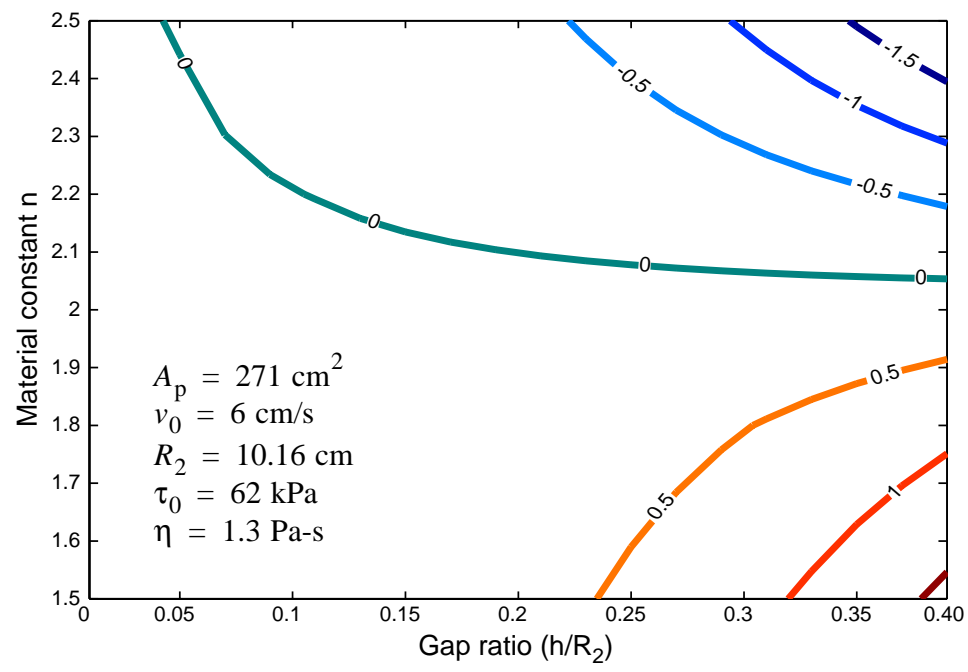

Fig. 6. Error comparison between axisymmetric and parallel-plate models.

\subsection{Quasi-static experimental results}

Fig. 7 shows the experimental setup that was constructed for damper testing. The damper is attached to a $7.5 \mathrm{~cm}$-thick plate that is grouted to a $2 \mathrm{~m}$-thick strong floor. The damper is driven by a $560 \mathrm{kN}$ actuator configured with a $305 \mathrm{lpm}$ servo-valve with a bandwidth of $80 \mathrm{~Hz}$. A Schenck-Pegasus 5910 servo-hydraulic controller is employed in conjunction with a $200 \mathrm{MPa}$, $340 \mathrm{lpm}$ hydraulic pump. The displacement of the damper is measured using a position sensor, and a force transducer connected to the actuator measures the force.

Fig. 8a shows the measured force-displacement loops for the damper under $5.92 \mathrm{~cm} / \mathrm{sec}$ tri-

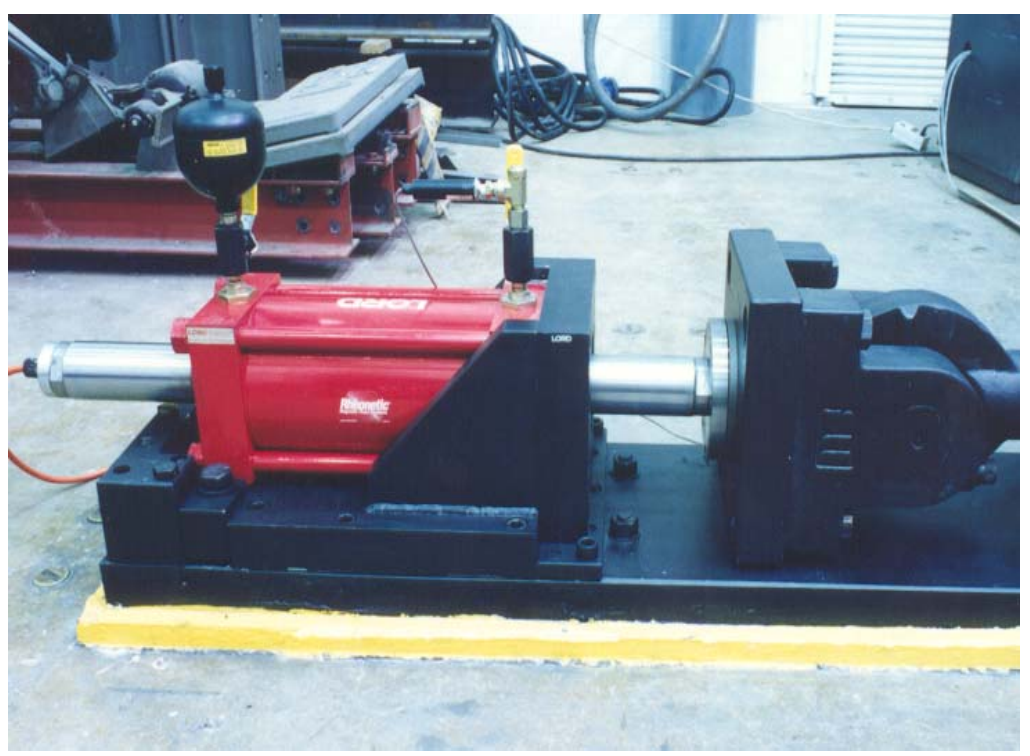

Fig. 7. Experimental setup for 20-ton full-scale MR fluid damper. 
(a)

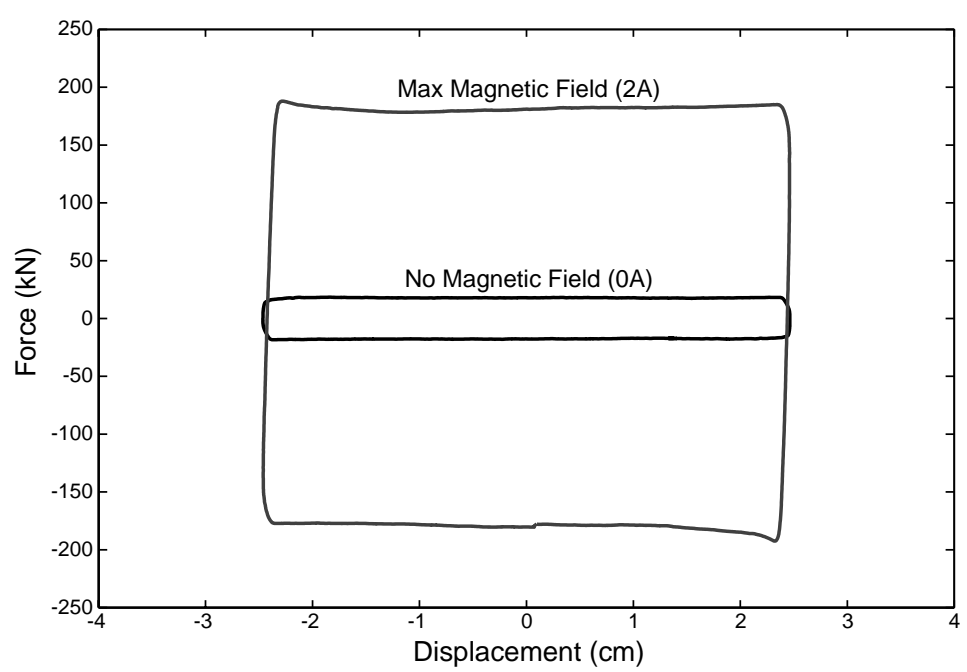

(b)

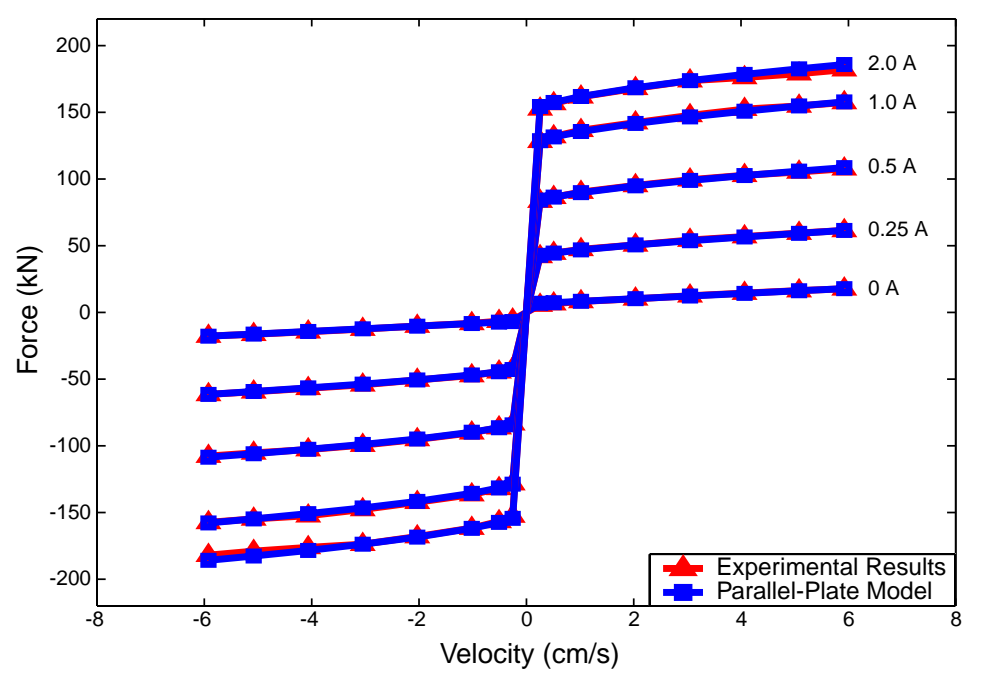

Fig. 8. (a) Measured force-displacement loops at the velocity of $5.92 \mathrm{~cm} / \mathrm{sec}$;

(b) Comparison of measured and predicted force-velocity behavior.

angular waveform movements with the maximum magnetic field applied and with no applied magnetic field, respectively. Under application of the maximum magnetic field, the resisting force of the damper is $182.1 \mathrm{kN}$-within $9 \%$ of the design specification of $200 \mathrm{kN}$. The controllable force is $164.38 \mathrm{kN}$. Moreover, the dynamic range of the damper is 10.29 , which is within $0.3 \%$ of the design specification of 10 .

Fig. $8 \mathrm{~b}$ shows the measured force-velocity relationship and compares this with the parallelplate model results. In the calculation, the friction force is $6.34 \mathrm{kN}$, as obtained from the experimental result. The yield stress is chosen such that the experimental results match the theoretical results at the velocity of $3 \mathrm{~cm} / \mathrm{s}$. The analytical model is in close agreement with the experimental results, having a maximum error of less than $2.5 \%$. 


\section{Basic geometry design considerations}

Based on the parallel-plate model developed and validated in the previous section, simple equations that provide the insight as to the impact of various parameter are given; these equations can be readily used for initial design. Also, the effects of geometry on MR damper performance, controllable force and dynamic range, are discussed.

\subsection{Controllable force and dynamic range}

Controllable force and dynamic range are the two most important parameters used in evaluating the overall performance of MR dampers. As illustrated in Fig. 9, the damper resisting force can be decomposed into a controllable force $F_{\tau}$ due to controllable yield stress $\tau_{0}$ and an uncontrollable force $F_{\mathrm{uc}}$. The uncontrollable force includes a viscous force $F_{\eta}$ and a friction force $F_{f}$. The dynamic range is defined as the ratio between the total damper output force $F$ and the uncontrollable force $F_{\mathrm{uc}}$ as follows:

$$
D=\frac{F}{F_{\mathrm{uc}}}=1+\frac{F_{\tau}}{F_{\eta}+F_{f}}
$$

Based on the parallel-plate model, $F_{\eta}$ and $F_{\tau}$ are defined as:

$$
F_{\eta}=\left(1+\frac{w h v_{0}}{2 Q}\right) \frac{12 \eta Q L A_{\mathrm{p}}}{w h^{3}}
$$

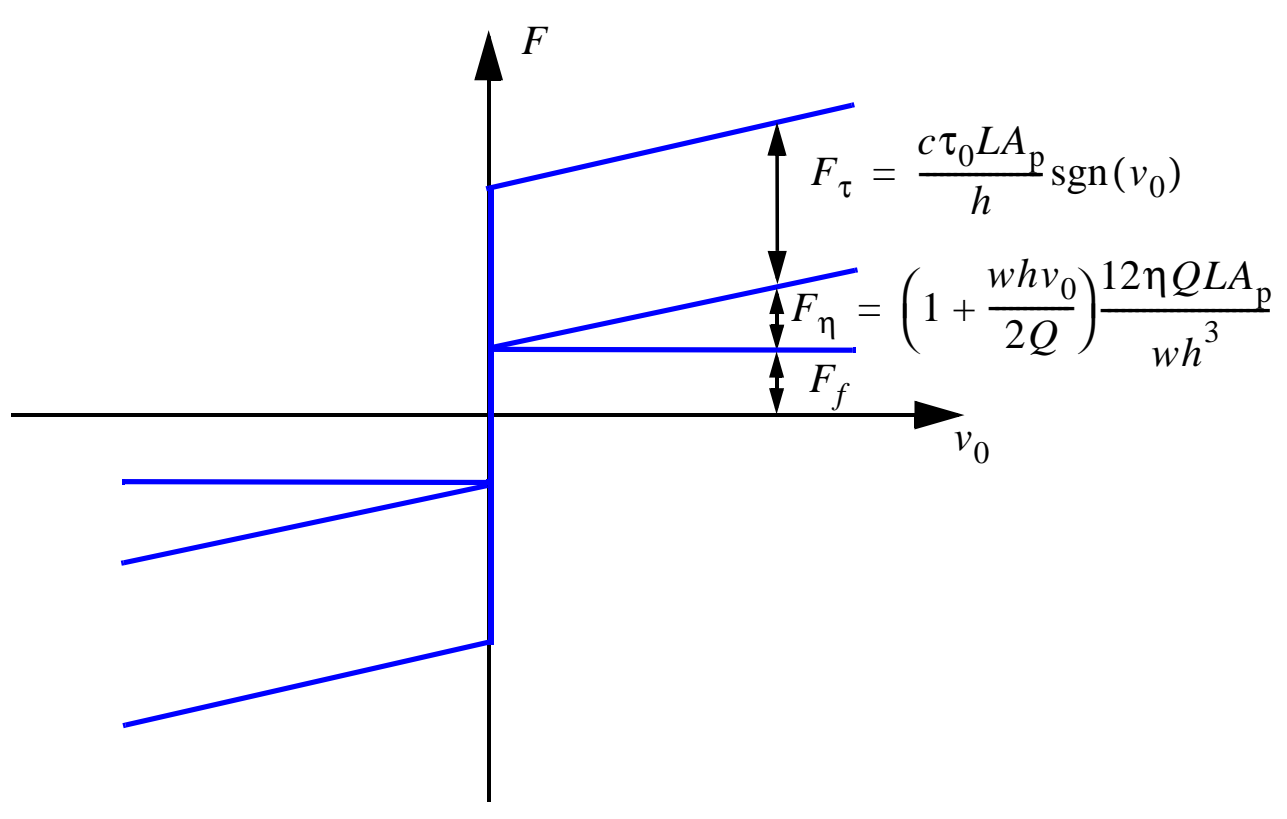

Fig. 9. Illustration of force decomposition of MR dampers. 


$$
F_{\tau}=c \frac{\tau_{0} L A_{p}}{h} \operatorname{sgn}\left(v_{0}\right)
$$

and $c \approx 2.07+1 /(1+0.4 \mathcal{T})$ bounded to the interval [2.07,3.07] [16].

The controllable force in Eq. (29) can also be rewritten using Eq. (24) as

$$
F_{\tau}=\left(2.07+\frac{12 Q \eta}{12 Q \eta+0.4 w h^{2} \tau_{0}}\right) \frac{\tau_{0} L A_{p}}{h} \operatorname{sgn}\left(v_{0}\right)
$$

which indicates that the controllable force range is inversely related to the gap size $h$. To maximize the effectiveness of the MR damper, the controllable force should be as large as possible; therefore, a small gap size is required.

However, a small gap size decreases the dynamic range. As can be seen from Eqs. (29) and (30), the viscous force increases two orders of magnitude faster than the controllable force with a small gap size, assuming that the magnetic field is saturated; consequently, the dynamic range tends to zero. Both the controllable force and viscous force decrease as the gap size increases. Note that the friction force is a constant; again, the dynamic range tends to zero. It is obvious that an optimal dynamic range must exist.

Fig. 10 provides a typical relationship between gap size, dynamic range and controllable force. For the design parameters of the 20-ton full-scale MR damper, the maximum dynamic range is 11.77 with a gap ratio of 0.028 , and the controllable force is $113.46 \mathrm{kN}$. In the current design, the gap size is $2 \mathrm{~mm}$ corresponding to the gap ratio of 0.0197 . Therefore, the dynamic range and controllable force obtained from theoretical calculation, as shown in Fig. 10, are 10.45 and $165.18 \mathrm{kN}$, respectively. When compared with the experimental results illustrated in section 4.4, where the dynamic range is 10.28 and the controllable force is $164.38 \mathrm{kN}$, an error of less than $1.5 \%$ is observed.
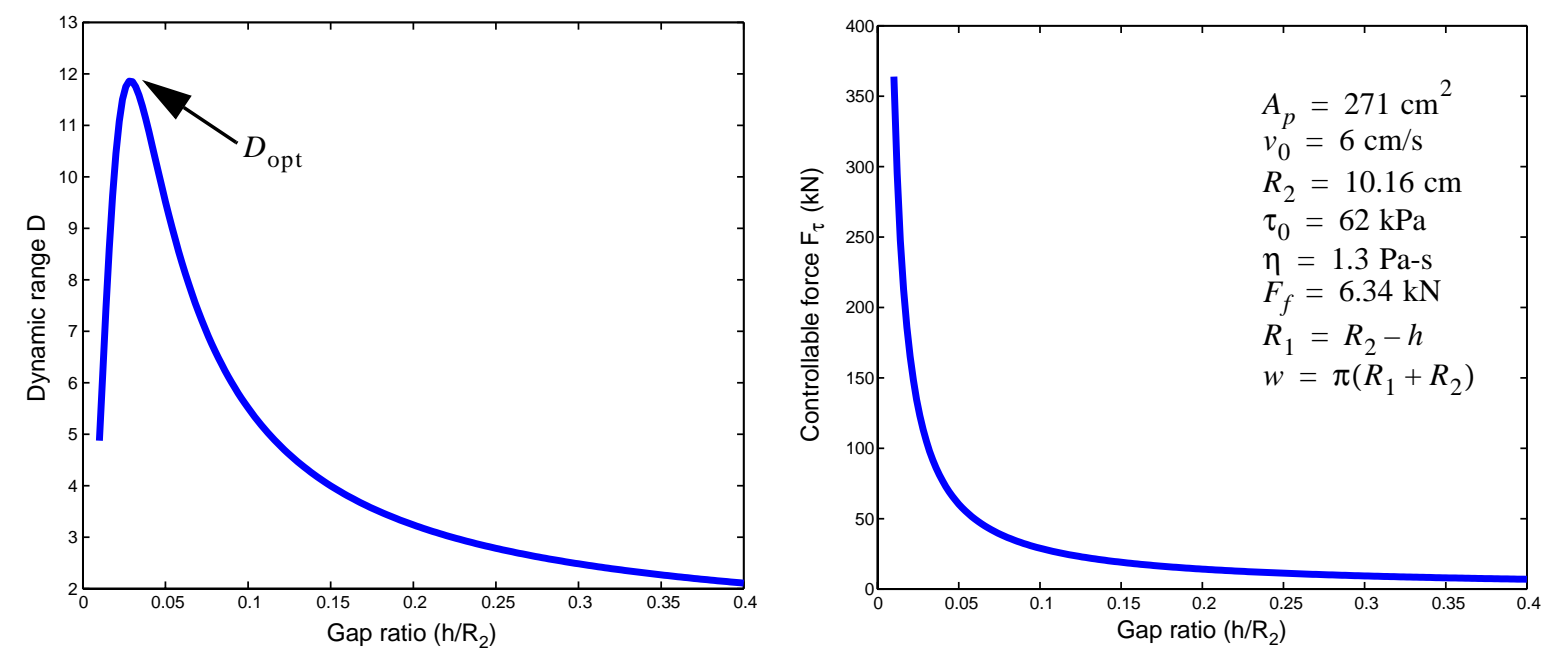

Fig. 10. Relationship between gap size, dynamic range $D$ and controllable force. 


\subsection{Geometry constraints}

Eqs. (29) and (30) are certainly useful in the design of MR dampers; however, they often do not provide the best insight into the significance of various parameters. Therefore, the minimum active fluid volume $V$ is introduced. This is the volume of MR fluids exposed to the magnetic field, and thus it is responsible for providing the desired MR effect. Eqs. (29) and (30) can be rewritten as [9]

$$
V=\frac{12 k}{c^{2}}\left(\frac{\eta}{\tau_{0}^{2}}\right)\left(\frac{F_{\tau}}{F_{\eta}}\right) Q \Delta p_{\tau}
$$

where $V=L w h ; k=1+\left(w h v_{0}\right) /(2 Q)$; and $\Delta p_{\tau}=$ pressure drop due to the yield stress. Eq. (32) can be further manipulated to give

$$
w h^{2}=\frac{12 k}{c}\left(\frac{\eta}{\tau_{0}}\right)\left(\frac{F_{\tau}}{F_{\eta}}\right) Q
$$

Note that for most of design cases, $w h v_{0} \ll Q$, and therefore, $k \approx 1$.

For the initial geometric design of MR dampers, one can assume that the friction force $F_{\tau}$ has the same order as the viscous force $F_{\eta}$. Thus, $F_{\tau} / F_{\eta} \approx 2 D$, where $D$ is the required dynamic range. By knowing the required damper flow rate $Q$, dynamic range $D$, cylinder size $w$, yield stress $\tau_{0}$, plastic viscosity $\eta$, and pressure drop $\Delta p_{\tau}$, the gap size $h$ and active pole length $L$ can be obtained from Eqs. (32) and (33). However, this initial design needs to be verified by a more accurate axisymmetric model. Typically, a detailed design also involves iterations with the magnetic circuit design.

\section{Dynamic modeling of MR dampers}

Although the quasi-static models developed previously are useful for MR damper design, they are not sufficient to describe the dynamic behavior of MR dampers. As a direct extension of the Bingham plasticity model, an idealized mechanical model was proposed by Stanway et al. [54]. In this model, a Coulomb friction element is placed in parallel with a linear viscous damper. The force-displacement behavior appears to be reasonably modeled; however, this model does not exhibit the observed nonlinear force-velocity response, especially when the displacement and velocity have the same sign and the magnitude of the velocity is small [14]. A more accurate dynamic model of MR dampers is necessary for analysis and synthesis of structures employing MR dampers.

Two types of dynamic models for controllable fluid dampers have been investigated by researchers: non-parametric models and parametric models. Ehrgott and Masri [3] and Gavin et al. [5] presented a non-parametric approach employing orthogonal Chebychev polynomials to predict the damper output force using the damper displacement and velocity information. Chang 


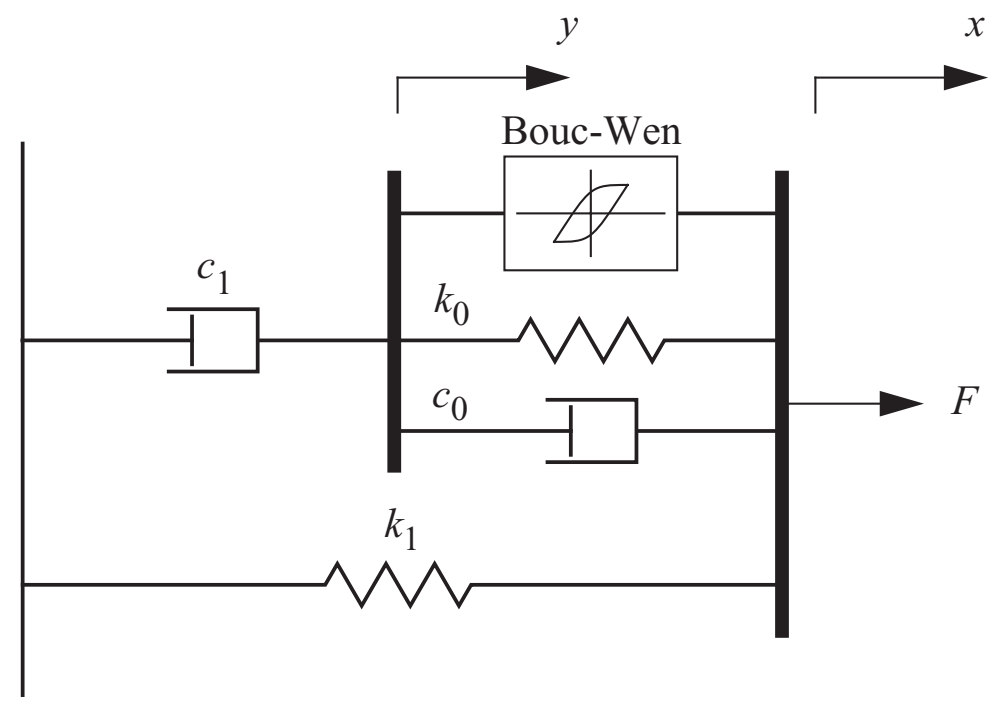

Fig. 11. Mechanical model of MR dampers [14].

and Roschke [55] developed a neural network model to emulate the dynamic behavior of MR dampers. However, the non-parametric damper models are quite complicated. Gamato and Filisko [56] proposed a parametric viscoelastic-plastic model based on the Bingham model. Wereley et al. [7] developed a nonlinear hysteretic biviscous model, which is an extension of the nonlinear biviscous model having an improved representation of the pre-yield hysteresis. However, these models can not readily capture the force roll-off in the low velocity region that is observed in the experimental data.

Spencer et al. [14] proposed a mechanical model for MR dampers based on the Bouc-Wen hysteresis model that overcomes a number of difficulties mentioned previously. The schematic of the model is shown in Fig. 11. In this model, the total force is given by

$$
F=\alpha z+c_{0}(\dot{x}-\dot{y})+k_{0}(x-y)+k_{1}\left(x-x_{0}\right)=c_{1} \dot{y}+k_{1}\left(x-x_{0}\right)
$$

where $z$ and $y$ is governed by

$$
\begin{gathered}
\dot{z}=-\gamma|\dot{x}-\dot{y}| z|z|^{n-1}-\beta(\dot{x}-\dot{y})|z|^{n}+A(\dot{x}-\dot{y}) \\
\dot{y}=\frac{1}{c_{0}+c_{1}}\left\{\alpha z+c_{0} \dot{x}+k_{0}(x-y)\right\}
\end{gathered}
$$

in which $k_{1}=$ accumulator stiffness; $c_{0}=$ viscous damping at large velocities; $c_{1}=$ viscous damping for force roll-off at low velocities; $k_{0}=$ stiffness at large velocities; and $x_{0}=$ initial displacement of spring $k_{1}$.

To determine a model which is valid under fluctuating input current, the functional depen- 
dence of the parameters on the input current must be determined. Since the fluid yield stress is dependent on input current, $\alpha$ can be assumed as a function of the input current $i$. Moreover, from the experiment results, $c_{0}$, and $c_{1}$ are also functions of the input current.

Assume that functions of $\alpha, c_{0}$, and $c_{1}$ have the form of a third order polynomial. For the 20-ton full-scale MR damper, the optimal identified equations for $\alpha, c_{0}$, and $c_{1}$ are

$$
\begin{gathered}
\alpha(i)=16566 i^{3}-87071 i^{2}+168326 i+15114 \\
c_{0}(i)=437097 i^{3}-1545407 i^{2}+1641376 i+457741 \\
c_{1}(i)=-9363108 i^{3}+5334183 i^{2}+48788640 i-2791630
\end{gathered}
$$

and the rest of identified parameters are given in Table 2. Moreover, a first-order filter is also used

Table 2: Identified parameters for the full-scale 20-ton MR damper.

\begin{tabular}{|c|c||c|c|}
\hline Parameter & Value & Parameter & Value \\
\hline $\mathrm{A}$ & $2679 \mathrm{~m}^{-1}$ & $\mathrm{n}$ & 10 \\
\hline$\gamma, \beta$ & $647.46 \mathrm{~m}^{-1}$ & $x_{0}$ & $0.18 \mathrm{~m}$ \\
\hline$k_{0}$ & $137810 \mathrm{~N} / \mathrm{m}$ & $k_{1}$ & $617.31 \mathrm{~N} / \mathrm{m}$ \\
\hline
\end{tabular}

to accommodate the dynamics involved in the MR fluid reaching rheological equilibrium

$$
H(s)=\frac{31.4}{s+31.4}
$$

Fig. 12 provides a comparison between the predicted and experimentally-obtained responses under a $1 \mathrm{~Hz}, 0.5$ inch sinusoidal displacement excitation using the proposed mechanical model for the MR damper. The proposed model predicts the damper behavior very well in all regions, including in the region where the velocities are small. Figs. 13 and 14 provide the comparison between the measured and predicted force under random displacement excitation. Fig. 13 shows the result with a constant input current of $1 \mathrm{~A}$, and result with random input current is provided in Fig. 14. As can be seen, the experimental and model responses match very well. 
(a)

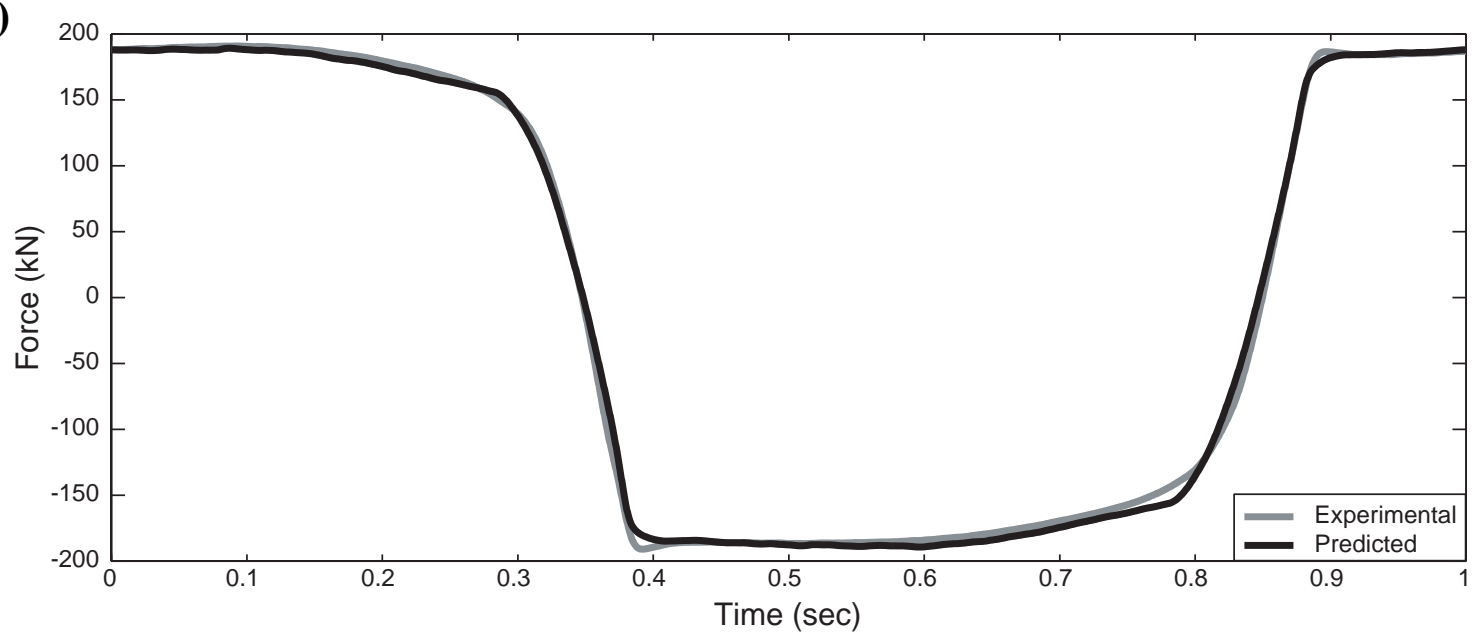

(b)

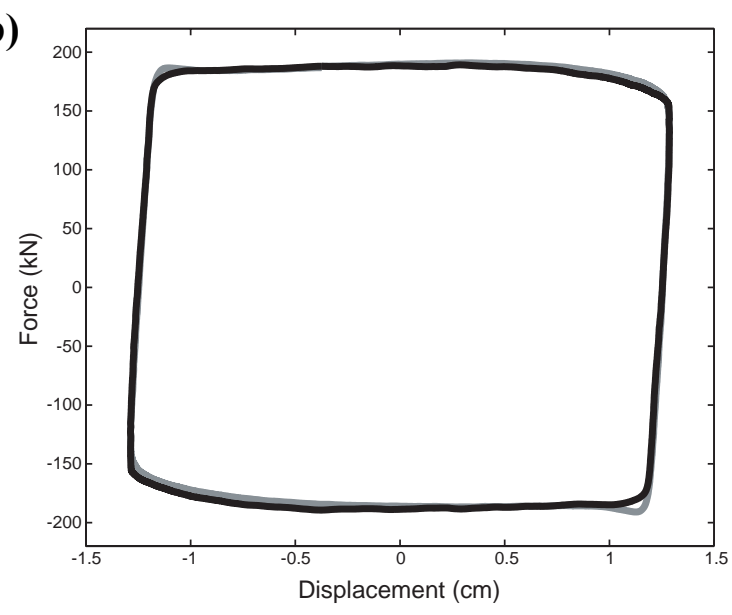

(c)

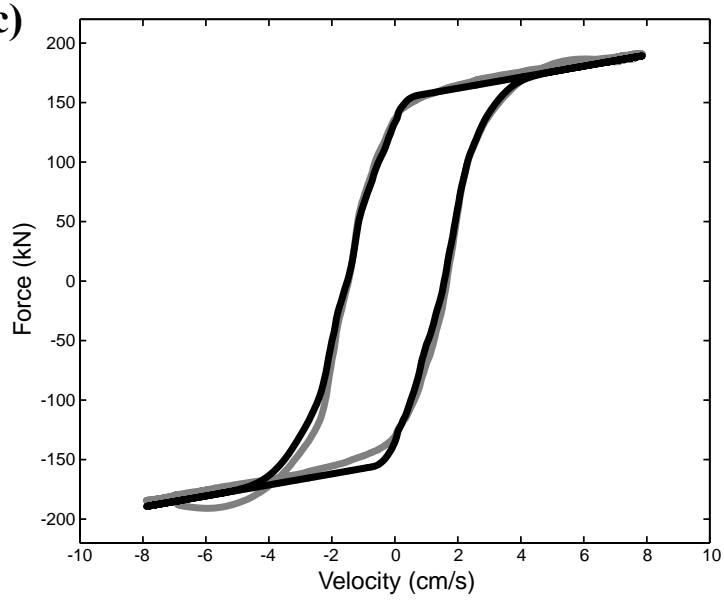

Fig. 12. Comparison between the predicted and experimentally-obtained response under $1.0 \mathrm{~Hz}, 0.5$ inch sinusoidal displacement excitation with constant input current of 2 A input using the proposed mechanical model of the MR damper:

(a) Force vs. time; (b) force vs. displacement; and (c) force vs. velocity.

\section{Dynamic performance considerations of MR dampers}

\subsection{Dynamic performance of the MR damper electromagnet}

The magnetic field, and thus the force produced by an MR damper, is directly related to the current in the damper's electromagnetic coil. Neglecting eddy currents in the steel, the basic behavior of this electromagnetic circuit can be modeled by using an electrical network in which a resistor and an inductor are connected in series, as shown in Fig. 15.

The equation governing the current $i(t)$ in the coil is

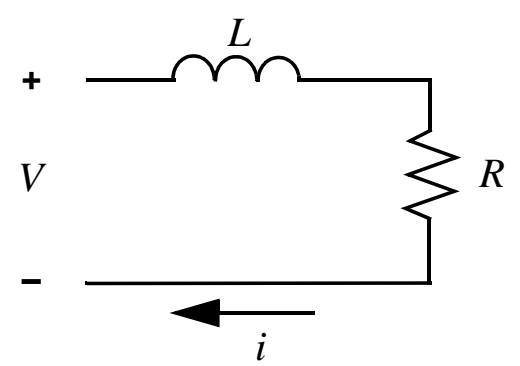

Fig. 15. Simple model of the electromagnet circuit. 
(a)

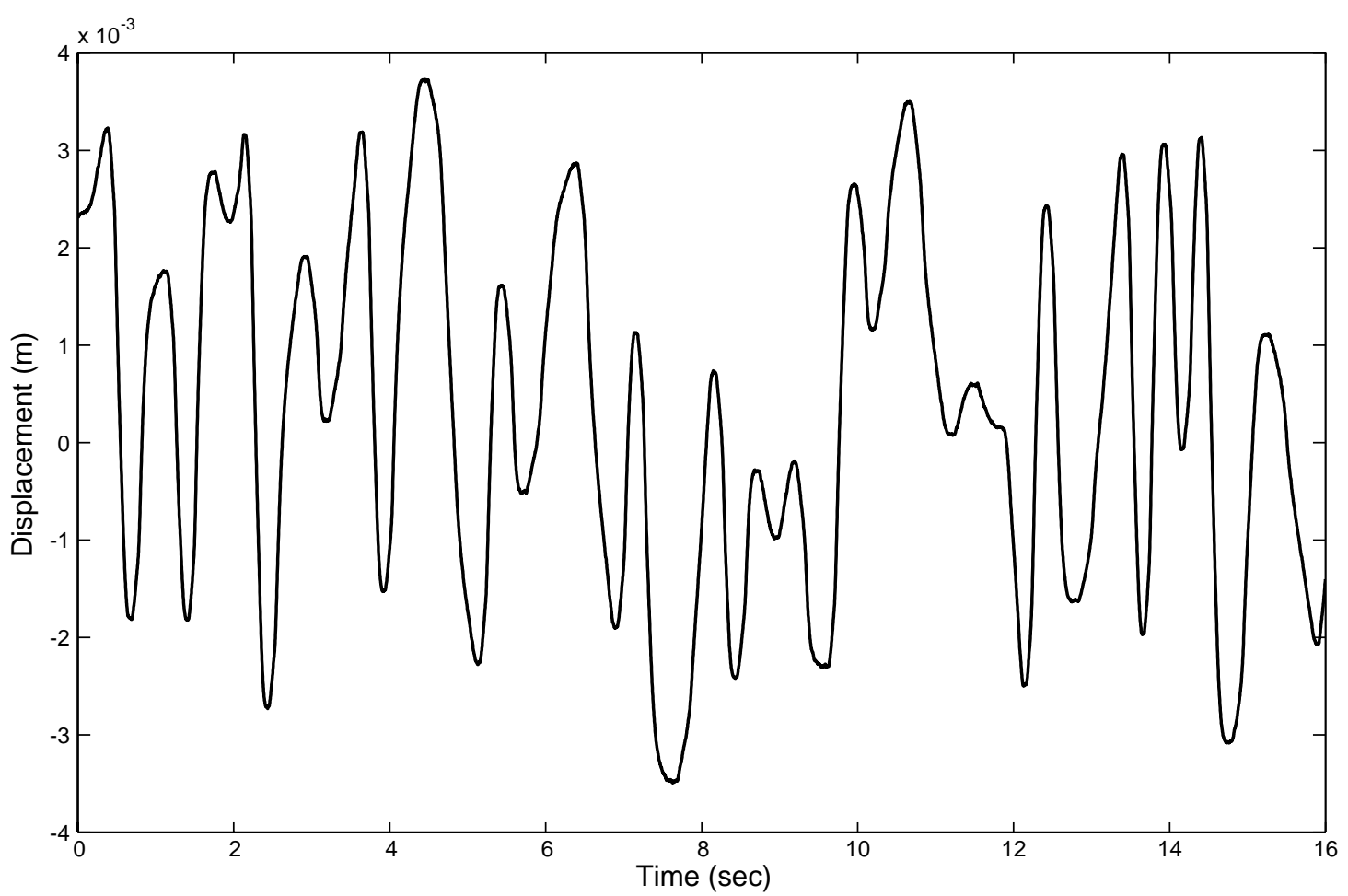

(b)

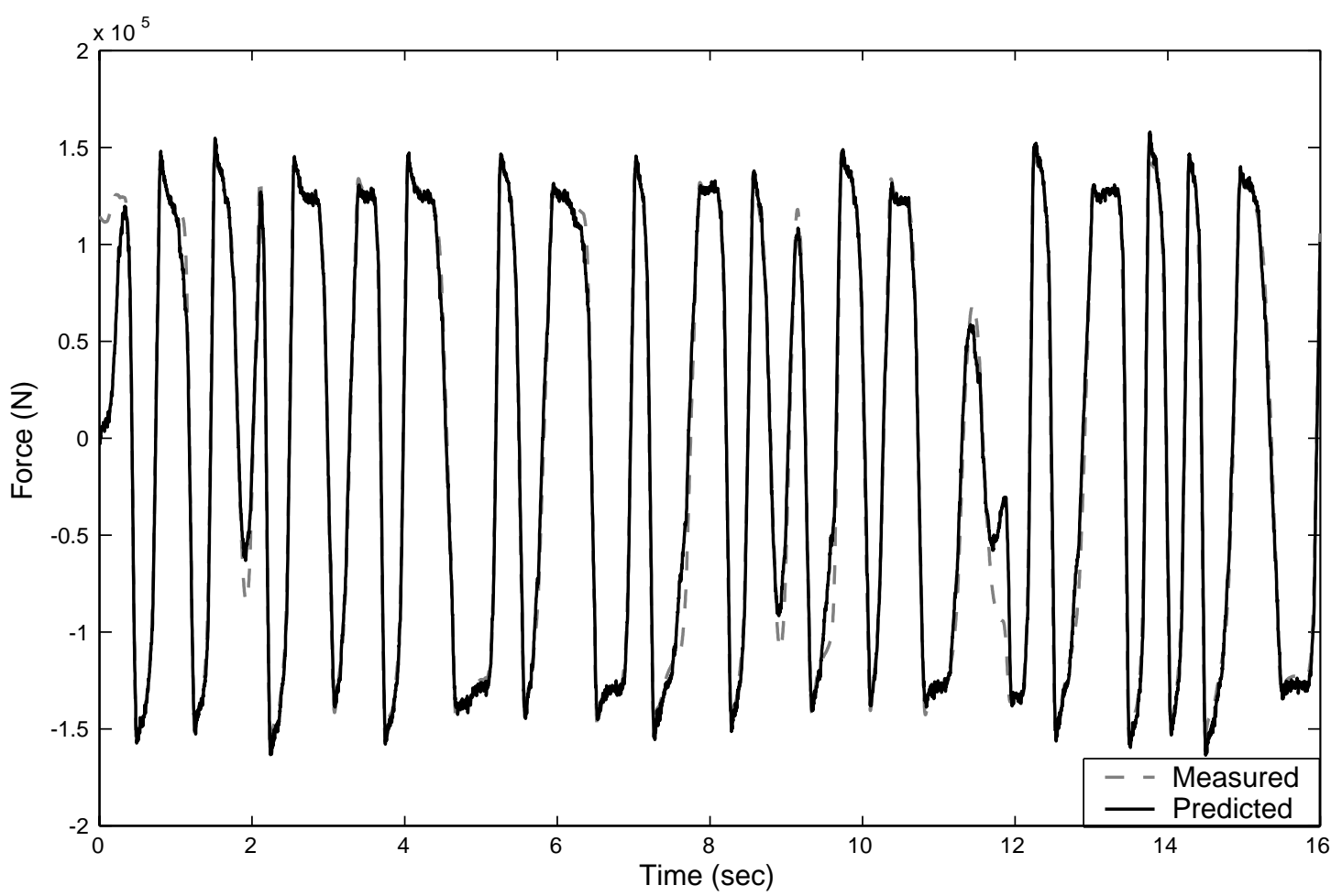

Fig. 13. (a) Measured random displacement excitation; (b) Force comparison between experimental data and model results under a constant input current of $1 \mathrm{~A}$. 
(a)

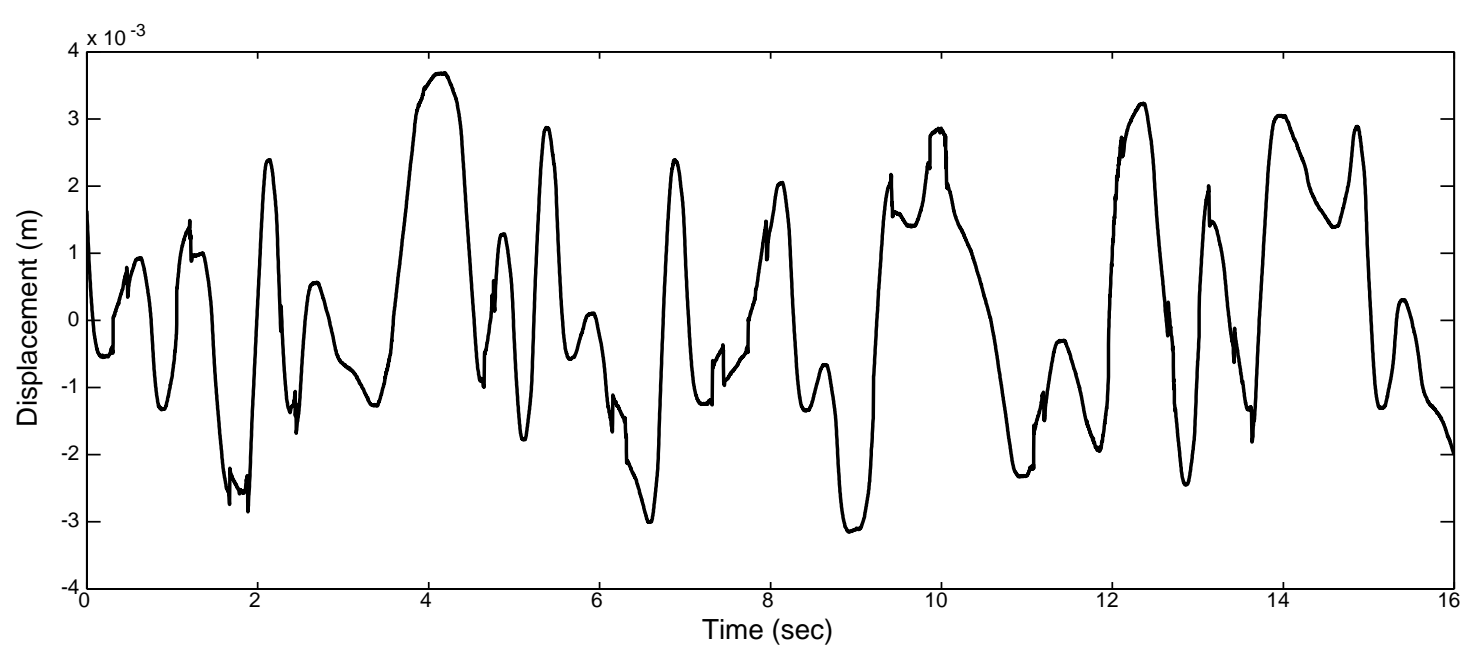

(b)

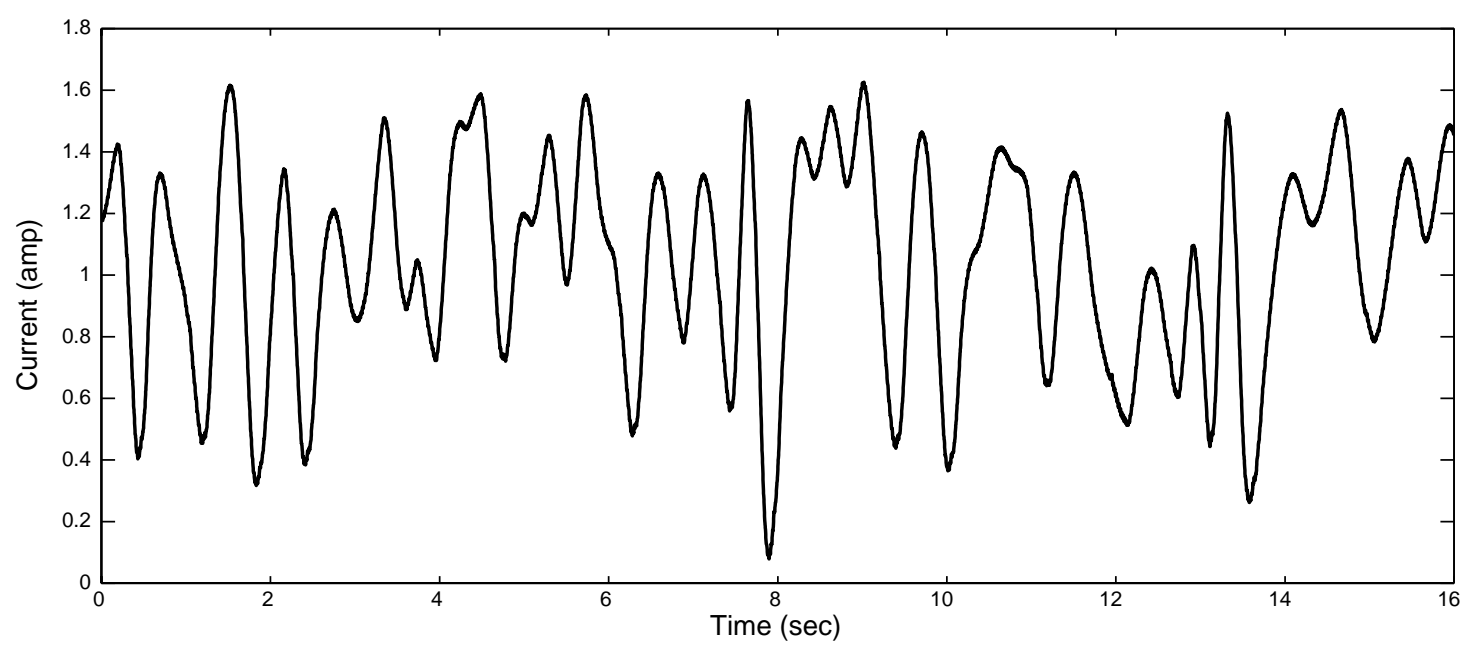

(c)

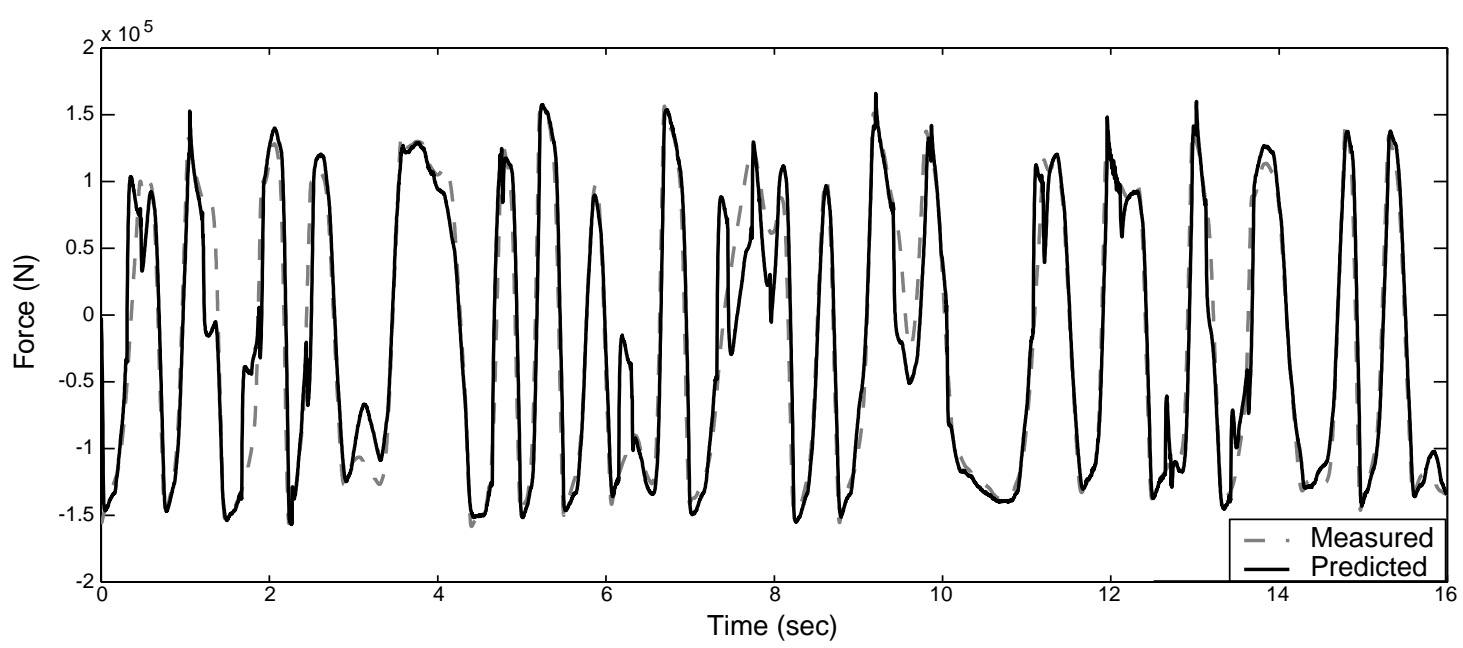

Fig. 14. (a) Measured random displacement excitation; (b) measured random input current; (c) force comparison between experimental data and model results with random input current. 


$$
L \frac{d}{d t} i(t)+R i(t)=V(t)
$$

where $L$ and $R=$ coil inductance and resistance, respectively; and $V=$ input voltage. Assuming a constant voltage $V_{0}$, the solution for (41) is

$$
i(t)=\frac{V_{0}}{R}\left(1-e^{-\frac{R}{L} t}\right)
$$

Eq. (42) indicates that nearly $3 L / R$ seconds are required for the current to reach $95 \%$ of the final value $V / R$. This exponential response is insufficient for many practical applications.

\subsection{Current Driver}

Several approaches can be considered to decrease the response time of the MR damper's magnetic circuit. The first is to use a current driver instead of a voltage-driven power supply. To see the effect of the current driver, the feedback loop given by

$$
\frac{d}{d t} V(t)=\gamma\left\{i_{\mathrm{d}}-i(t)\right\}
$$

is combined with Eq. (41) to yield the governing equation for current as

$$
L \frac{d^{2} i}{d t^{2}}+R \frac{d i}{d t}+\gamma i=\gamma i_{\mathrm{d}}
$$

where $i_{\mathrm{d}}=$ desired current; and $\gamma=$ proportional gain. By adjusting the gain $\gamma$ such that the system is under damped $(\zeta=R /(2 \sqrt{\gamma L})<1)$, faster response times can be achieved. Assuming that the voltage does not saturate, the first point in at which the achieved current reaches the desired current $i_{\mathrm{d}}$ is

$$
t_{1}=\frac{2 L}{R} \frac{(\pi-\arctan \beta)}{\beta}
$$

where $\beta=\sqrt{(4 \gamma L) / R^{2}-1}$.

\subsection{Amplifier Saturation Voltage and Coil Configuration}

The MR damper shown in Fig. 2 has a multi-stage electromagnetic coil. These coils may be connected in series or parallel. For this discussion, assume that the total inductance and resistance of the coils connected in series are $L_{0}$ and $R_{0}$, respectively. Assuming that the damper has $n$ identical coils, then the effective inductance and resistance of the coils connected in parallel are 


$$
L_{\text {parallel }}=\frac{L_{0}}{n^{2}}, \quad R_{\text {parallel }}=\frac{R_{0}}{n^{2}}
$$

For both series and parallel configurations, the ratio $L / R=L_{0} / R_{0}$, and the power requirements to produce a given current $i_{\mathrm{d}}$ in the coils is $i_{\mathrm{d}}^{2} R_{0}$. However, the time $t_{0}$ to reach the current $i_{\mathrm{d}}$ is not the same.

When using a current driver with a relatively large gain $\gamma$, a step input command causes the current driver to output the maximum amplifier voltage $V_{\max }$. For this case, the time to reach the current $i_{\mathrm{d}}$ is

$$
t_{0}=-\frac{L_{0}}{R_{0}} \ln \left(1-\frac{R_{0} i_{\mathrm{d}}}{n V_{\max }}\right)
$$

where $i_{\mathrm{d}}<V_{\max } / R_{0}$. Expanding in terms of $1 / n$, Eq. (47) can be approximated as

$$
t_{0}=\frac{L_{0} i_{\mathrm{d}}}{V_{\max }}\left(\frac{1}{n}\right)+\frac{L_{0} R_{0} i_{\mathrm{d}}^{2}}{2 V_{\max }^{2}}\left(\frac{1}{n^{2}}\right)+\ldots
$$

Experience indicates that $V_{\text {max }}$ should be several times larger than $i_{\mathrm{d}} R_{0}$; consequently, retaining only the first term in the series provides a reasonably good estimate for $t_{0}$. The time to reach a desired current $i_{\mathrm{d}}$ is approximately inversely proportional to the number $n$ of coils in the magnetic circuit and the maximum voltage $V_{\max }$ of the amplifier. Therefore, reduced damper response times can be achieved by using the parallel coil configuration and increasing the maximum voltage achievable by the current driver.

\subsection{Force-feedback control}

The resisting force of an MR damper depends on the input current to the electromagnet, the characteristics of MR fluids, the motion of the damper, and the damper's geometry. Moreover, the damper resisting force is not proportional to the input current, as is shown in Fig. 8b. Therefore, commanding the MR damper to output an arbitrary force is not straightforward. To overcome this difficulty, a force-feedback control scheme is employed, as shown in Fig. 16. In this approach, there are two control blocks, a force upside control block and a force downside control block. These are triggered by the decision block. In the upside control block, a traditional PID controller with a large proportional gain is used such that when the force error is large, the current driver uses its full capacity or voltage to increase the current in the coil; consequently, the damper resisting force is also increases. In the downside control block, a current back-driven technique is used when the force error is large; this technique work by applying a negative current, as opposed to simply reducing the input current or setting the current back to zero. The results presented in the next section employ the force-feedback control strategy. 


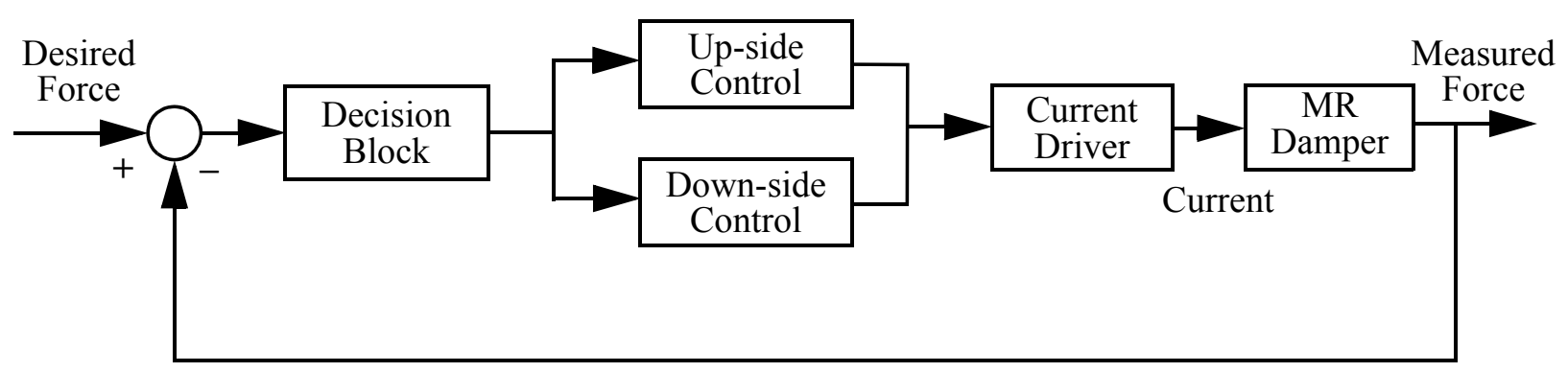

Fig. 16. Block diagram of force-feedback control strategy.

\subsection{Experimental verification}

Fig. 17 compares the current in the 20-ton MR damper coil (connected in series) that result from a step input command generated by both constant voltage and current-driven power supplies. In the constant voltage case, a voltage-driven power supply is attached to the damper coils. The time constant $L_{0} / R_{0}$ for the coils of the 20-ton MR damper arranged in series is $0.3 \mathrm{sec}$. Therefore, as shown in Fig. 17, it takes about $1 \mathrm{sec}$ for the current to achieve 95\% of the final value which indicates that the damper has only a $1 \mathrm{~Hz}$ bandwidth. Alternatively, using a current driver, the $5 \%$ range is achieved within $0.06 \mathrm{sec}$. The current driver includes a DC power supply $( \pm 120 \mathrm{~V})$ and a PWM servo amplifier manufactured by the Advanced Motion Controls operating under current mode. Because the current driver clearly offers a substantial reductions in the

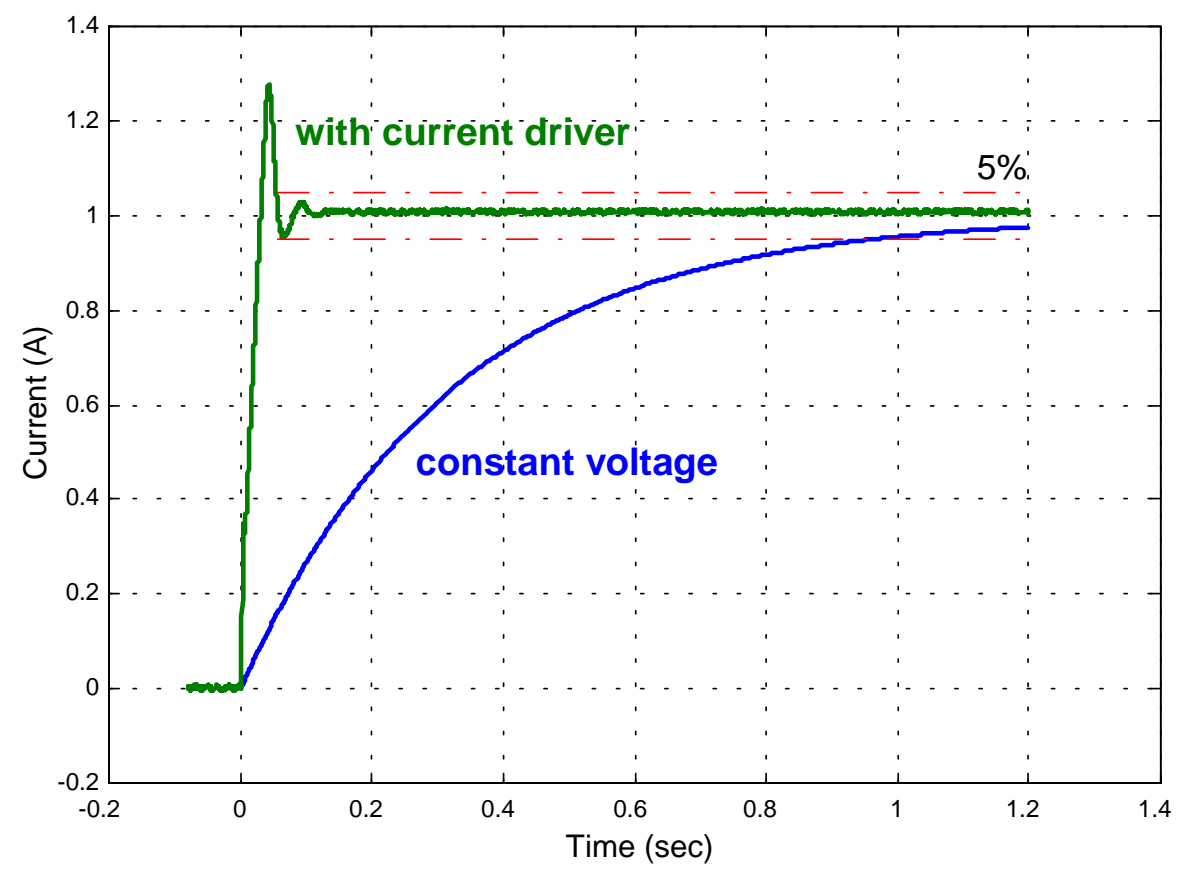

Fig. 17. Comparison between current in coil when driven by constant voltage and current-driven power supply. 
response time, the subsequent results reported herein will employ this current driver.

Figs. 18 and 19 illustrate the performance difference between the series-coil and parallelcoil connections of the MR damper force response to a step input current when the damper moves at a constant velocity of $1 \mathrm{~cm} / \mathrm{sec}$. For the series connection, nearly 0.39 seconds is required for force to rise from $7.85 \mathrm{kN}$ to $157.9 \mathrm{kN}$, and 0.16 seconds are required for the force to drop from $158.5 \mathrm{kN}$ to $70 \mathrm{kN}$. However, the parallel connection requires only 0.2 seconds for force to rise from $7.85 \mathrm{kN}$ to $157.9 \mathrm{kN}$; and 0.115 seconds to drop from $158.5 \mathrm{kN}$ to $70 \mathrm{kN}$. Note that $7.85 \mathrm{kN}$ is the off-state force corresponding to zero input current.

From Fig. 18, note that more than a full second is required to drop the force from $158.5 \mathrm{kN}$ to off-state force $7.85 \mathrm{kN}$ for both connections-much longer than the upside. The reason for this phenomenon is due to the residual magnetic field remaining inside the damper after the current has been removed. To overcome this problem, the coils are back-driven at the maximum allow-
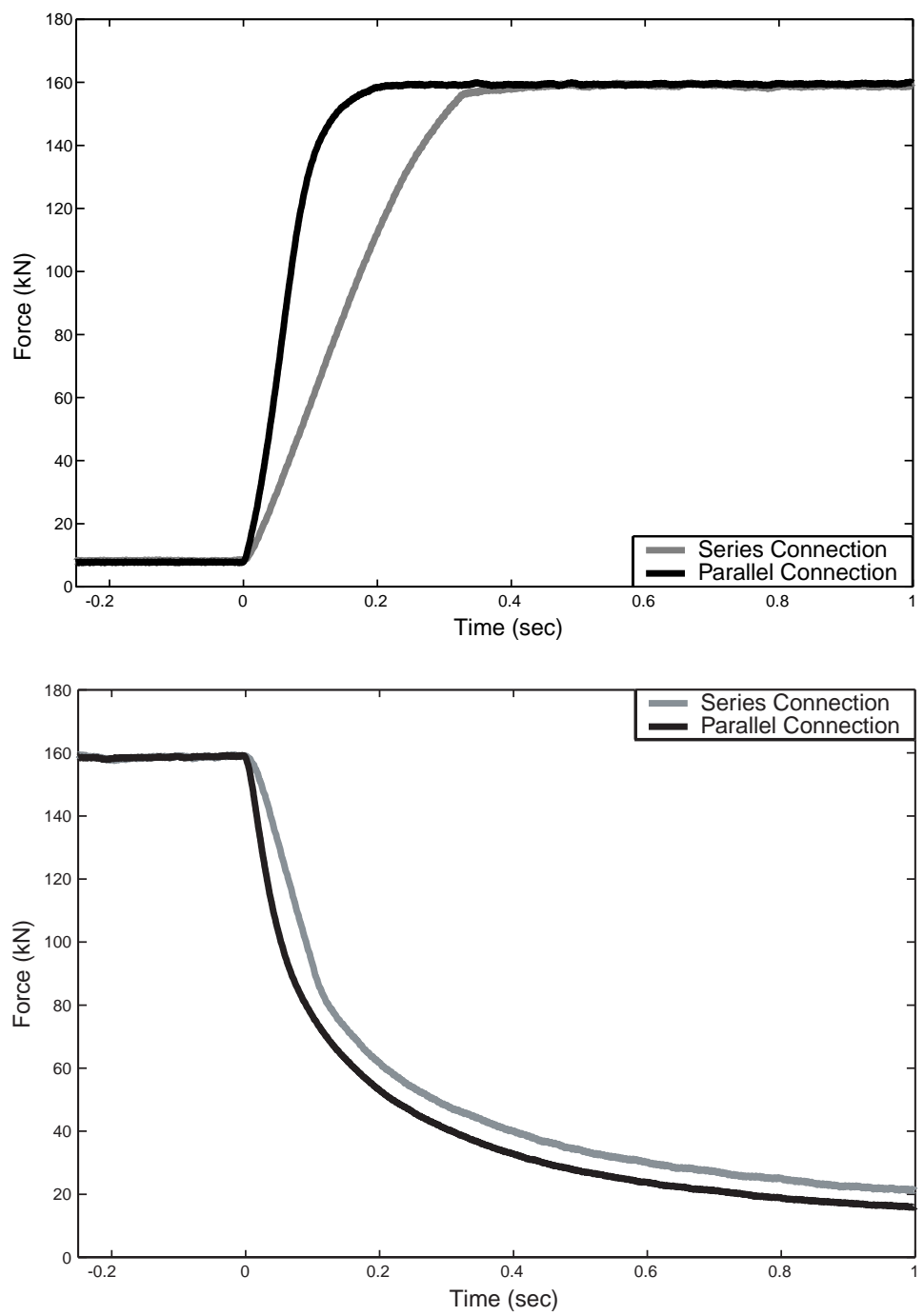

Fig. 18. MR damper response time using series and parallel connections with current driver. 
able value of -6 A (when connected in parallel; i.e., $-2 \mathrm{~A}$ in each oil) until the damper force reaches its off-state value. As illustrated in Fig. 19, the use of the back-driven current approach requires only 0.099 seconds to command the damper force from $158.5 \mathrm{kN}$ to the off-state force of $7.85 \mathrm{kN}$ in parallel connection. The back-driven current approach can effectively reduce the influence of the residual magnetic field, allowing a fast response time to be achieved on the downside of the damper force.

\section{Conclusions}

Magnetorheological (MR) fluid dampers provide a level of technology that has enabled effective semi-active control in a number of real world applications. Because of their simplicity, low input power, scalability and inherent robustness, such MR fluid dampers appear to be quite promising for civil engineering applications. A 20-ton MR damper capable of providing semiactive damping for full-scale structural applications has been designed and constructed.

For design purposes, two quasi-static models, an axisymmetric and a parallel-plate model, are derived for the force-velocity relationship of the MR damper, and both models present results which closely match the experimental data. Experimental results have also shown that MR dampers can provide large controllable damping forces, while requiring only a small amount of energy. Moreover, a mechanical model is employed to model the dynamic behavior of the MR damper.

Dynamic response time is another important characteristic affecting in the performance of MR dampers in practical civil engineering applications. A current driver has been shown to be effective in reducing the response time of the MR damper. Experimental results show that a parallel connection of the damper coils results in faster response time than a series connection. For the parallel connection, only 0.2 seconds are needed to achieve $157.9 \mathrm{kN}$ in the upside of the damper force; and 0.099 seconds are needed to reduce the damper force from $158.5 \mathrm{kN}$ to $7.85 \mathrm{kN}$ (off

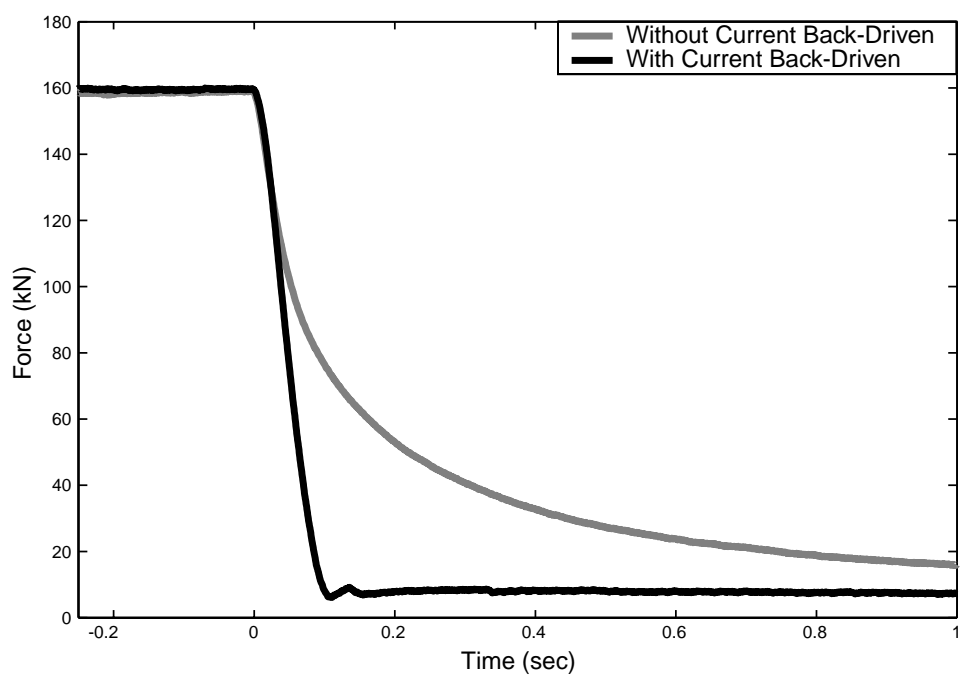

Fig. 19. Damper response time using current back-driven approach. 
state) on the downside using current back-driven approach. The experimental results indicate that the response time of the damper is adequate for a wide range of civil engineering structural applications.

\section{Acknowledgement}

The authors gratefully acknowledge the support of this research by the National Science Foundation under grant CMS 99-00234 (Dr. S.C. Liu, Program Director) and the LoRD Corporation.

\section{References}

[1] Soong, TT, Spencer Jr., BF. Supplemental energy dissipation: state-of-the-art and state-of-the-practice. Engineering Structures, 2001, submitted.

[2] Housner GW et al. Structural control: past, present, and future. J of Engineering Mechanics, ASCE 1997;123(9):897-971.

[3] Ehrgott RC, Masri SF. Modeling the oscillatory dynamic behavior of electrorheological materials in shear. Smart Materials and Structures 1992;1:275-85.

[4] Gavin HP, Hanson RD, Filisko FE. Electrorheological dampers, part 1: analysis and design. J of Applied Mechanics, ASME 1996a;63(9):669-75.

[5] Gavin HP, Hanson RD, Filisko FE. Electrorheological dampers, part 2: testing and modeling. J of Applied Mechanics, ASME 1996b;63(9):676-82.

[6] Makris N, Burton SA, Hill D, Jordan M. Analysis and design of ER damper for seismic protection of structures. J of Engineering Mechanics, ASCE 1996;122(10):1003-11.

[7] Wereley NM, Pang L, Kamath GM. Idealized hysteresis modeling of electrorheological and magnetorheological dampers. J of Intelligent Material, Systems and Structures 1998;9(8):642-49.

[8] Carlson JD, Spencer Jr. BF. Magneto-rheological fluid dampers for semi-active seismic control. Proceedings of 3rd International Conference on Motion and Vibration Control, vol. 3, Chiba, Japan, 1996. pp. 35-40.

[9] Carlson JD, Spencer Jr. BF. Magneto-rheological fluid dampers: scalability and design issues for application to dynamic hazard mitigation. Proceedings of 2nd Workshop on Structural Control: Next Generation of Intelligent Structures, Hong Kong, China, 1996. pp. 99-109.

[10] Dyke SJ, Spencer Jr. BF, Sain MK, Carlson JD. Modeling and control of magnetorheological dampers for seismic response reduction. Smart Materials and Structures 1996;5:565-75.

[11] Fujitani H, Sodeyama H, Hata K, Iwata N. Komatsu Y. Sunakoda K. Soda S. Dynamic performance evaluation of magneto-rheological damper. Proceeding of International Conference on Advances in Structural Dynamics, vol. 1, Hong Kong, China, 2000. pp. 319-26.

[12] Jansen, LM, Dyke SJ. Semiactive control strategies for MR dampers: comparative study. J of Engineering Mechanics, ASCE 2000;126(8):795-803. 
[13] Spencer Jr. BF, Dyke SJ, Sain MK. Magnetorheological dampers: a new approach to seismic protection of structures. Proceedings of Conference on Decision and Control, Kobe, Japan, 1996. pp. 67681 .

[14] Spencer Jr. BF, Dyke SJ, Sain MK, Carlson JD. Phenomenological model of a magnetorheological damper. J of Engineering Mechanics, ASCE 1997;123(3):230-38.

[15] Spencer Jr. BF, Carlson JD, Sain MK, Yang G. On the current status of magnetorheological dampers: seismic protection of full-scale structures. Proceedings of American Control Conference, Albuquerque, New Mexico, 1997. pp. 458-62.

[16] Spencer Jr. BF, Yang G, Carlson JD, Sain MK. Smart dampers for seismic protection of structures: a full-scale study. Proceedings of 2nd World Conference on Structural Control, vol. 1, Kyoto, Japan, 1998. pp. 417-26.

[17] Spencer Jr. BF, Johnson EA, Ramallo JC. "Smart" isolation for seismic control. JSME International Journal, JSME 2000;43(3):704-11.

[18] Sunakoda K, Sodeyama H, Iwata N, Fujitani H, Soda S. Dynamic characteristics of magneto-rheological fluid damper. Proceedings of SPIE Smart Structure and Materials Conference, vol. 3989, Newport Beach, California, 2000. pp. 194-203.

[19] Yang G, Ramallo JC, Spencer Jr. BF, Carlson JD, Sain MK. Dynamic Performance of large-scale MR fluid dampers. Proceedings of 14th ASCE Engineering Mechanics Conference, Austin, Texas, 2000.

[20] Yang G, Ramallo JC, Spencer Jr. BF, Carlson JD, Sain MK. Large-scale MR fluid dampers: dynamic performance considerations. Proceedings of International Conference on Advances in Structure Dynamics, vol. 1, Hong Kong, China, 2000. pp. 341-48.

[21] Kurata N, Kobori T, Takahashi M, Niwa N. Semi-active damper system in large earthquake. Proceedings of 2nd World Conference on Structural Control, vol. 1, Kyoto, Japan, 1998, pp. 359-66.

[22] Kurata N, Kobori T, Takahashi M, Niwa N, Midorikawa H. Actual seismic response controlled building with semi-active damper system. Earthquake Engineering and Structural Dynamics 1999;28:1427-48.

[23] Patten WN. The I-35 Walnut Creek Bridge: an intelligent highway bridge via semi-active structural control. Proceedings of 2nd World Conference on Structural Control, vol. 1, Kyoto, Japan, 1998, pp. 427-36.

[24] Patten WN. Field test of an intelligent stiffener for bridges at the I-35 Walnut Creek Bridge. Earthquake Engineering and Structural Dynamics 1999;28:109-26.

[25] Symans MD, Constantinou MC. Seismic testing of a building structure with a semi-active fluid damper control system. Earthquake Engineering and Structural Dynamics 1997;26:759-77.

[26] Akbay Z, Aktan HM. Intelligent energy dissipation devices. Proceedings of the 4th U.S. National Conference on Earthquake Engineering, vol. 3, Palm Springs, California, 1990. pp. 427-35.

[27] Akbay Z, Aktan HM. Actively regulated friction slip devices. Proceedings of 6th Canadian Conference on Earthquake Engineering, Toronto, Canada, 1991. pp. 367-74.

[28] Akbay Z, Aktan HM. Abating earthquake effects on buildings by active slip brace devices. Shock Vibration $1995 ; 2: 133-42$ 
[29] Dodwell DJ, Cherry S. Structural control using semi-active friction damper. Proceedings of 1st World Conference on Structural Control, Los Angeles, California, 1994. FA1, pp. 59-68.

[30] Feng Q, Shinozuka M, Fujii S. Friction controllable sliding isolated system. J of Engineering Mechanics 1993;119(9):1845-64.

[31] Inaudi JA. Modulated homogeneous friction: a semi-active damping strategy. Earthquake Engineering and Structural Dynamics 1997;26(3):361-76.

[32] Kobri T, Takahashi M, Nasu T, Niwa N, Ogasawara K. Seismic response controlled structure with active variable stiffness system. Earthquake Engineering and Structural Dynamics 1993;22:925-41.

[33] Nagarajaiah S, Matte D. Semi-active control of continuously variable stiffness system. Proceedings of 2nd World Conference on Structural Control, vol. 1, Kyoto, Japan, 1998, pp. 398-405.

[34] Nagarajaiah S, Varadarajan N. Novel semi-active variable stiffness tuned mass damper with real time retuning capability. Proceedings of 14th Engineering Mechanics Conference, Austin, TX, 2000.

[35] Nemir DC, Lin Y, Osegueda RA. Semiactive motion control using variable stiffness. J of Structural Engineering 1994;120(4):1291-306.

[36] Yamada K, Kobori T. Control algorithm for estimating future responses of active variable stiffness structure. Earthquake Engineering and Structural Dynamics 1995;24:1085-99.

[37] Yang JN, Wu JC, Li Z. Control of seismic excited buildings using active variable stiffness systems. Engineering Structures 1996;18(8):589-96.

[38] Johnson EA, Baker GA, Spencer Jr. BF, Fujino, Y. Semiactive damping of stay cables. J of Engineering Mechanics, ASCE, 2001, accepted.

[39] Johnson EA, Christenson RE, Spencer Jr. BF. Semiactive damping of cables with sag. ComputerAided Civil Infrastructure Engineering, 2001, accepted.

[40] Yoshioka H, Ramallo JC, Spencer Jr. BF. "Smart" base isolation strategies employing magnetorheological dampers. J of Engineering Mechanics, ASCE, 2001, submitted.

[41] Rabinow J. The magnetic fluid clutch. AIEE Transactions 1948;67:1308-15.

[42] Rabinow J. Magnetic fluid torque and force transmitting device. U.S. Patent 2,575,360, 1951.

[43] Phillips RW. Engineering applications of fluids with a variable yield stress. Ph.D thesis, University of California, Berkeley, California, 1969.

[44] Lee DY, Wereley NM. Analysis of electro- and magneto-rheological flow mode dampers using Herschel-Bulkley model. Proceedings of SPIE Smart Structure and Materials Conference, vol. 3989, Newport Beach, California, 2000. pp. 244-52.

[45] Wang X, Gordaninejad F. Study of field-controllable, electro- and magneto-rheological fluid dampers in flow mode using Herschel-Bulkley theory. Proceedings of SPIE Smart Structure and Materials Conference, vol. 3989, Newport Beach, California, 2000. pp. 232-43.

[46] Weiss KD, Duclos TG. Controllable fluids: the temperature dependence of post-yield properties. Proceedings of the Fourth International Conference on ER Fluids (Tao R, Roy GD, World Scientific, Singapore), 1994, pp. 43-59.

[47] Carlson JD, Weiss KD. A growing attraction to magnetic fluids. Machine Design 1994;8:61-6. 
[48] Carlson JD. The promise of controllable fluids. Proceedings of Actuator 94 (Borgmann H, Lenz K, AXON Technologie), 1994. pp. 266-70.

[49] Carlson JD, Catanzarite DM, St. Clair KA. Commercial magneto-rheological fluid devices. Proceedings of 5th international conference on ER fluids, MR fluids and associated technologies (Bullough WA, World Scientific, Singapore), 1996, pp. 20-8.

[50] Spencer Jr. BF, Sain MK. Controlling buildings: a new frontier in feedback. IEEE Control System Magazine: Special Issue on Emerging Technology, 1997;17(6):19-35.

[51] Wereley NM, Pang L. Nondimensional analysis of semi-active electrorheological and magnetorheological dampers using approximate parallel plate models. Smart Materials and Structures, 1998;7:732-43.

[52] Kamath GM, Hurt MK, Wereley NM. Analysis and testing of Bingham plastic behavior in semi-active electrorheological fluid dampers. Smart Materials and Structures, 1996;5:576-90.

[53] Constantinescu VN. Laminar Viscous Flow, New York: Springer, 1995.

[54] Stanway R, Sproston JL, Stevens NG. None-linear modelling of an electro-rheological vibration damper. J of Electrostatics 1987;20:167-84.

[55] Chang CC, Roschke P. Neural network modeling of a magnetorheological damper. J of Intelligent Material Systems and Structures 1998;9(9):755-64.

[56] Gamota DR, Filisko FE. Dynamic mechanical studies of electrorheological materials: moderate frequencies. J of Rheology 1991;35:399-425. 